\title{
Subsidizing Renewable Energy under Capital Mobility
}

\author{
Thomas Eichner \\ Marco Runkel
}

\author{
CESIFO WORKING PAPER NO. 3185 \\ CATEGORY 10: ENERGY AND CLIMATE ECONOMICS \\ SEPTEMBER 2010
}
An electronic version of the paper may be downloaded
- from the SSRN website:
- from the RePEc website:
- from the CESifo website:
www.SSRN.com
www.RePEc.org
www.CESifo-group.org/wp




\title{
Subsidizing Renewable Energy under Capital Mobility
}

\begin{abstract}
This paper provides a rationale for subsidizing green (renewable) energy production. Within a multi-country model where energy is produced with mobile capital in green and dirty production, we investigate the countries' decentralized choice of emissions taxes and green energy subsidies. Without green subsidies, the emissions tax is set inefficiently low, since each country ignores the environmental externality inflicted on other countries and since the emissions tax leads to a capital outflow to other countries. When the green subsidy is available, countries choose a positive subsidy rate since this reduces the overall distortion of the tax-subsidy system. In doing so, each country internalizes a larger part of the environmental externality. As consequence capital is relocated from the dirty into the clean sectors and reduces global pollution. Hence, the subsidy is not only beneficial for the country which imposes it but for all countries.
\end{abstract}

JEL-Code: H71, Q42, Q58.

Keywords: renewable energy, capital mobility, green subsidy, emissions regulation.

\author{
Thomas Eichner \\ Department of Economics \\ University of Hagen \\ Universitätsstrasse 41 \\ 58097 Hagen \\ Germany \\ thomas.eichner@fernuni-hagen.de
}

\author{
Marco Runkel \\ Faculty of Economics and Management \\ University of Magdeburg \\ P.O. Box 4120 \\ 39016 Magdeburg \\ Germany \\ marco.runkel@ovgu.de
}

September 15, 2010

We would like to thank participants of the World Congress of Environmental and Resource Economists in Montreal, the Public Finance Council meeting of the German Economic Association in Budapest and research seminars in Leipzig and Magdeburg for their helpful comments. The usual disclaimer applies. 


\section{Introduction}

Classical energy production relies on fossil fuels like oil, natural gas and coal. At this production there emerges as by-product carbon dioxide which is the most important greenhouse gas since a too high concentration of it in the atmosphere accelerates climate change and causes environmental damage. Renewable energies like solar and wind do not generate greenhouse gases and hence do not harm the environment. In order to fulfill the emissions reduction commitment of the Kyoto protocol and to contribute to the mitigation of climate change, a large number of countries have implemented policy measures for promoting renewable energies. For example, as of 2009 more than 60 countries worldwide use Feed-In-Tariffs which guarantee suppliers of renewable energy a price that lies above the market price, implying an implicit subsidy on renewable energy. Other widely used policy measures are Renewable Energy Portfolio Standards (used in many U.S. states), tax incentives or direct R\&D subsidies (used mainly in European countries). ${ }^{1}$ Giving this evidence, the present paper addresses the question whether there is an economic rationale for subsidizing renewable energy production.

Standard arguments from environmental economics suggest the following answer. Energy producers that use fossil fuels emit greenhouse gases without taking into account the environmental damage caused by climate change. The resulting environmental externality can be internalized, in a cost-effective way, either by a Pigouvian emissions tax on the polluting energy sector or by a cap-and-trade system where polluting energy producers have to buy permits for each unit of their emissions. Green subsidies paid to the renewable energy sector are then not only unnecessary, they even reduce efficiency by distorting the decisions of energy producers without contributing to the internalization of environmental externalities. ${ }^{2}$ At first glance, one should expect that this distortion is aggravated in an international context with mobile capital and decentralized environmental policy of countries. The reason is that the uncoordinated choice of environmental policy instruments would result in a detrimental subsidy competition among countries, since each country tries to attract firms and investments and to raise employment by overbidding the green subsidies paid by other countries.

In stark contrast to this view, our analysis identifies an argument in favor of subsi-

\footnotetext{
${ }^{1} \mathrm{~A}$ comprehensive survey of policy instrument promoting renewable energy is given in the CESifo database DICE under http://www.cesifo-group.de/portal/page/portal/ifoHome/a-winfo/d3iiv.

${ }^{2}$ Such an argument has currently been brought forward by, e.g., Johnstone (2003) who argues that the mix of policy instruments '... will be at best redundant and at worst counterproductive.'
} 
dizing renewable energy. We show that under capital mobility and decentralized policy choice, a green subsidy is not only in the interest of the country imposing the subsidy, but it also lowers global emissions of greenhouse gases and therefore benefits all countries. This argument is made within a stylized multi-country model. Each country hosts two energy sectors. The first sector produces energy with the help of a dirty technology (fossil fuels) which generates emissions. These emissions cause environmental damage not only in the country where the emissions originate, but also in the other countries. The second sector uses a green technology to produce energy without emissions (renewable energy). Both sectors employ internationally mobile capital as production input. We first determine the centralized (first-best) capital allocation which is characterized by the condition that the marginal return to capital in the dirty sector is equal to the opportunity costs of capital (in form of the forgone marginal return to investments in the green sector) and the marginal environmental damage.

Against this benchmark result, we investigate the efficiency properties of decentralized environmental policy making. Under decentralization, each country chooses its policy instruments such as to maximize welfare of its residents, taking as given the policy choice of the other countries. If green energy subsidies are not available, emissions taxes are inefficient for two reasons. First, in setting the emissions tax rate each government takes into account the environmental damage in its own country, but not the environmental damage in the other countries. Second, from the point of view of the individual country the emissions tax distorts the investment decision of the dirty sector since it increases the user costs of capital in this sector and thereby leads to a capital outflow to other sectors and, in particular, to other countries. Both reasons induce the individual country to set its emissions tax rate inefficiently low, i.e. lower than the world-wide marginal environmental damage. The distorted policy choice, in turn, causes overinvestment in the dirty sector and underinvestment in the green sector.

If green energy subsidies are at the governments' disposal, the subsidy distorts investment decisions in the green sector since it lowers the user costs of capital in this sector and ceteris paribus leads to overinvestment in green energy production. But both the distortion caused by the emissions tax and the distortion caused by the green subsidy increase overproportionally with the tax/subsidy rate. Then, mixing the emissions tax with the green subsidy reduces the overall distortion of the tax-subsidy system, and hence each country has an incentive to choose a positive green subsidy rate. In so doing, each country is able to internalize a larger part of the environmental externality caused by the emissions of its dirty sector. As consequence, capital is 
relocated from the dirty sectors to the green sectors, the capital allocation becomes more efficient and global emissions fall. The use of the green subsidy is therefore beneficial not only for the country which imposes it, but also for all other countries, even though the first-best capital allocation is still not attained.

This argument in favor of green subsidies turns out to be quite robust against modifications of the model. We explicitly consider two modifications. While in the basic model capital is in fixed supply, the first extension considers endogenous savings and capital supply. With fixed capital supply, the reduction in global emissions is achieved by a relocation of capital from dirty to clean sectors. In contrast, with endogenous savings the use of the green subsidy raises world-wide capital supply and, thus, has an additional positive effect on investment in both the clean and the dirty sectors. However, we show that the additional effect on investments in the dirty sectors is more than compensated by the reduction of dirty investment due to the larger internalization of the environmental externality. Moreover, the additional effect on green investments does not lead to overinvestment in the clean sectors. Put differently, even with endogenous savings, capital supply in the equilibrium of the policy game is always sufficiently inelastic in order to preserve our argument in favor of green subsidies.

The second modification turns to a different kind of environmental policy. Many countries tackle pollution problems with a cap-and-trade (emissions trading) system instead of emissions taxes. If all countries establish such a system, our argument in favor of green subsidies breaks down since the caps fix overall emissions and the green subsidy cannot further reduce them. But in practice not all countries use emissions trading or taxation. We therefore show that our argument in favor of green subsidies may even be strengthened in an asymmetric policy setting. This point is illustrated for the two-country case with one green country that chooses a cap-and-trade system and a green subsidy, and a dirty country, which totally abstains from environmental policy. In such a setting the incentive for the green country to use the green subsidy is even stronger than in the basic model since this country is capital exporter (due to the more stringent environmental regulation) and the subsidy raises the rate of return to capital. The green subsidy relocates capital from the dirty sector in the dirty country to the green sector in the green country and thus reduces global emissions. This is again beneficial for all countries, even though we now cannot exclude that overall the dirty country is harmed, since capital also flows out from its green sector.

As the use of green subsidies still fails to implement the first-best capital allocation, our argument in favor of promoting renewable energy is of the second-best type. It relies 
on several assumptions, most importantly on the assumptions that capital is mobile, that emissions cause global environmental damage and that there is no (world-wide) coordination of climate policy. While the first two assumptions are undisputable in the context of climate change, the assumption of missing policy coordination deserves more motivation. In the last decades there have been great efforts of the world community to implement common measures against climate change. The Kyoto protocol is the most important example for this kind of policy coordination. In 2012 the Kyoto protocol runs out and in 2009 at the Copenhagen summit the nations tried to find a comprehensive climate agreement with targets, actions and binding legislation for the time after 2012. However, the results of Copenhagen were disappointing since the countries only agreed to a rather weak political statement, the so-called Copenhagen Accord. In light of this experience of the Copenhagen summit, it seems unlikely that in the near future full coordination of climate policy will take place. Instead, to a large degree countries will choose their environmental policy decentrally, and we are left with the question of optimal climate policy in a decentralized, second-best world.

Our paper is part of a very small, but growing literature discussing economic rationales for subsidizing renewable energy. One argument is that green subsidies spur learning effects in renewable energy production and, due to learning spillovers between energy producers, are beneficial not only for the recipient of the subsidy, but also for the society at large. See, for example, Bläsi and Requate (2007), Fischer and Newell (2008) and Lehmann (2009) for a detailed analysis. A second rationale for green subsidies is identified by Eichner und Pethig (2009). They show that small open economies may have an incentive to subsidize renewable energy in order to compensate for the uncertainty of fossil fuel prices and to increase energy security. Finally, Eichner and Pethig (2010) investigate a union of countries with a common cap-and-trade system and show that permit-importing countries may have incentives to subsidize renewable energy in order to influence the permit price in their favor. In contrast to our analysis, however, all these studies ignore capital as a mobile input factor in energy production and, thus, do not make our point in favor of green subsidies. A further important difference is that in the present approach the green subsidy may be beneficial not only for the country imposing it, but also for the other countries. In Eichner and Pethig (2010), for example, all countries would be better off if the green subsidy is abolished.

The present paper is also related to the literature on environmental policy in the presence of mobile firms - also known as pollution haven literature. One basic argument in this literature is that mobile firms relocate their plants to countries with low 
environmental regulation, thereby giving countries the incentive to choose inefficiently lax environmental policy (e.g. Markusen et al. 1993, 1995; Motta and Thisse 1994; Hoel 1997; Ulph and Valentini 2001). This argument is similar to our inefficiency result in case the green subsidy is not available. Another strand of literature like Oates and Schwab (1988), Chao and Yu (1997) and Ogawa and Wildasin (2009) analyzes capital tax competition ${ }^{3}$ with environmental pollution. In contrast to our inefficiency result in the absence of green subsidies, Ogawa and Wildasin (2009) point out that decentralized decision making with mobile capital and global pollution implements the efficient allocation. But their result rests on the assumptions that countries additionally impose a non-distortionary lump-sum tax on households and that world-wide emissions are fixed. Both assumptions are absent in our analysis. Anyway, contrary to our approach, all above studies do not distinguish between dirty and clean production and, thus, ignore subsidies on renewable energy, which are the main focus of our analysis.

The remainder of the paper is organized as follows. Section 2 introduces the basic model. Sections 3 and 4 derive the main results by investigating centralized and decentralized policy choices. In Section 5 we discuss extensions and Section 6 concludes.

\section{Basic Assumptions}

Energy Sectors. We consider a model with $n \geq 2$ countries. Each country hosts two energy sectors, both acting as price-taker. Dirty and clean sectors employ different production technologies. While production in the dirty sector generates emissions that damage the environment, the clean sector fully avoids such emissions. An example is energy production from coal as the dirty sector, causing emissions of carbon dioxide, and renewable energy production as the clean sector.

In country $i \in\{1, \ldots, n\}$, the production technology of the dirty sector reads $X\left(k_{x i}\right)$, where $k_{x i}$ is capital input rented at the world interest rate $r>0$. The production function $X$ exhibits positive and decreasing marginal returns to capital, i.e. $X^{\prime}>0$ and $X^{\prime \prime}<0$. We follow Ogawa and Wildasin (2009) and assume that each unit of capital invested in the dirty sector generates a fixed amount of emissions such that $e_{x i}=\alpha k_{x i}$ with $\alpha>0$. These emissions may be taxed by the government of country $i$ at tax rate $\tau_{i}$. Normalizing the price of energy to one, after-tax profits of the dirty

\footnotetext{
${ }^{3}$ The capital tax competition literature goes back to Zodrow and Mieszkowski (1986) and Wilson (1986) and is surveyed by, for example, Wilson (1999) and Wilson and Wildasin (2004).
} 
sector in country $i$ can be written as

$$
\pi_{x i}=X\left(k_{x i}\right)-\left(r+\alpha \tau_{i}\right) k_{x i} .
$$

The first-order condition of profit maximization is

$$
X^{\prime}\left(k_{x i}\right)=r+\alpha \tau_{i}
$$

It equates the marginal return to capital in country $i$ 's dirty sector to the marginal user costs consisting of the interest rate and the emissions tax. Increasing country $i$ 's emissions tax thus raises the marginal user costs in country $i$ 's dirty sector.

The production technology in country $i$ 's clean sector is given by $Y\left(k_{y i}\right)$, with $k_{y i}$ representing capital input. The production function $Y$ has positive and decreasing marginal returns to capital, i.e. $Y^{\prime}>0$ and $Y^{\prime \prime}<0$. There are no emissions in the clean sector. The government of country $i$ may grant a subsidy $\sigma_{i}$ on each unit of capital invested in its clean sector. The after-subsidy profits of the clean sector in country $i$ can therefore be written as

$$
\pi_{y i}=Y\left(k_{y i}\right)-\left(r-\sigma_{i}\right) k_{y i}
$$

Maximizing these profits yields the first-order condition

$$
Y^{\prime}\left(k_{y i}\right)=r-\sigma_{i}
$$

According to condition (4), capital input in country $i$ 's clean sector is increased up to the point where the marginal return to capital just equals the interest rate less the green subsidy. An increase in country $i$ 's green subsidy rate thus lowers the marginal user costs of capital in the clean sector of country $i$.

Capital Market. Capital is assumed to be perfectly mobile across countries. Each country is endowed with $\bar{k}>0$ units of capital which it inelastically supplies on the world capital market. The capital market equilibrium condition reads

$$
\sum_{i=1}^{n}\left(k_{x i}+k_{y i}\right)=n \bar{k} .
$$

It equates world-wide capital demand from all sectors and countries and worldwide capital supply. Together with the first-order conditions (2) and (4) for $i \in\{1, \ldots, n\}$, the capital market equilibrium condition (5) determines the capital allocation $\left(k_{x i}, k_{y i}\right)$ 
for $i \in\{1, \ldots, n\}$ and the world interest rate $r$ as functions of the policy instruments $\left(\tau_{i}, \sigma_{i}\right)$ for $i \in\{1, \ldots, n\}$.

For later purposes, we need to know the impact of the policy instruments on the capital market equilibrium. The largest part of the analysis focuses on a symmetric situation with all countries having the same policy instruments $\tau_{i}=\tau$ and $\sigma_{i}=\sigma$. From (2), (4) and (5), it follows $k_{x i}=k_{x}, k_{y i}=k_{y}$ and $k_{x}+k_{y}=\bar{k}$. Totally differentiating (2), (4) and (5) and then applying the symmetry property, Appendix A proves

$$
\begin{aligned}
\frac{\partial r}{\partial \tau_{i}} & =-\frac{\alpha Y^{\prime \prime}}{n\left(X^{\prime \prime}+Y^{\prime \prime}\right)}<0, \\
\frac{\partial k_{x i}}{\partial \tau_{i}} & =\frac{\alpha\left[n X^{\prime \prime}+(n-1) Y^{\prime \prime}\right]}{n X^{\prime \prime}\left(X^{\prime \prime}+Y^{\prime \prime}\right)}<0, \\
\frac{\partial k_{x j}}{\partial \tau_{i}} & =-\frac{\alpha Y^{\prime \prime}}{n X^{\prime \prime}\left(X^{\prime \prime}+Y^{\prime \prime}\right)}>0, \quad j \neq i \\
\frac{\partial k_{y j}}{\partial \tau_{i}} & =-\frac{\alpha}{n\left(X^{\prime \prime}+Y^{\prime \prime}\right)}>0
\end{aligned}
$$

An increase in one country's emissions tax rate raises the user costs of capital in the dirty sector of this country. Hence, if country $i$ increases its emissions tax, capital flows from the dirty sector of country $i$ to the dirty sectors of the other countries and to the clean sectors of all countries, as shown by (7)-(9). The total investments in the dirty sectors fall in favor of higher investments in the clean sectors. According to (6), the relocation of capital is induced by a reduction in the interest rate. The effects of the green subsidy on the capital market equilibrium are given by

$$
\begin{aligned}
\frac{\partial r}{\partial \sigma_{i}} & =\frac{X^{\prime \prime}}{n\left(X^{\prime \prime}+Y^{\prime \prime}\right)}>0, \\
\frac{\partial k_{y i}}{\partial \sigma_{i}} & =-\frac{(n-1) X^{\prime \prime}+n Y^{\prime \prime}}{n Y^{\prime \prime}\left(X^{\prime \prime}+Y^{\prime \prime}\right)}>0, \\
\frac{\partial k_{y j}}{\partial \sigma_{i}} & =\frac{X^{\prime \prime}}{n Y^{\prime \prime}\left(X^{\prime \prime}+Y^{\prime \prime}\right)}<0, \quad j \neq i, \\
\frac{\partial k_{x j}}{\partial \sigma_{i}} & =\frac{1}{n\left(X^{\prime \prime}+Y^{\prime \prime}\right)}<0 .
\end{aligned}
$$

An increase in one country's green subsidy rate reduces the user costs of capital in the clean sector of this country. As shown by (11)-(13), raising country $i$ 's green subsidy rate therefore causes a capital flow from the clean sectors of the other countries and the dirty sectors of all countries to the clean sector of country $i$. The total investments in the clean sectors increase at the expense of lower investments in the dirty sectors. 
This relocation of capital between the sectors is brought about by an increase in the world interest rate, as formally shown by (10).

Emissions. Following Ogawa and Wildasin (2009) we differentiate between emissions generated by a country and emissions affecting a country. For the sake of distinctness, the latter is denoted as pollution. Recall that country $i$ generates emissions $e_{x i}=\alpha k_{x i}$. In contrast, pollution in country $i$ is given by

$$
e_{i}=\alpha k_{x i}+\alpha \beta \sum_{j \neq i}^{n} k_{x j},
$$

with $\beta \in[0,1]$. For $\beta=0$ pollution is local since country $i$ is affected only by its own emissions, but not by emissions generated in the other countries. This case serves as a benchmark only. More relevant for our purposes is $\beta>0$ and, in particular, $\beta=1$. In the latter case, pollution in country $i$ is represented by a global public bad, since $\beta=1$ implies $e_{i}=\alpha \sum_{j=1}^{n} k_{x j}=$ : $e$ and, hence, one unit of emissions generated by a country equally affects all countries. This modelling approximately captures carbon dioxide emissions and is appropriate for the climate problem at hand.

With the help of the comparative static results (6)-(13) we are in the position to determine the effects of changes in the policy instruments on pollution. Differentiating (14) with respect to country $i$ 's emissions tax rate and using (7) and (8) yields

$$
\begin{aligned}
& \frac{\partial e_{i}}{\partial \tau_{i}}=\alpha \frac{\partial k_{x i}}{\partial \tau_{i}}+\alpha \beta(n-1) \frac{\partial k_{x j}}{\partial \tau_{i}}=\frac{\alpha^{2}\left[n X^{\prime \prime}+(1-\beta)(n-1) Y^{\prime \prime}\right]}{n X^{\prime \prime}\left(X^{\prime \prime}+Y^{\prime \prime}\right)}<0, \\
& \frac{\partial e_{j}}{\partial \tau_{i}}=\alpha \beta \frac{\partial k_{x i}}{\partial \tau_{i}}+\alpha[1+\beta(n-2)] \frac{\partial k_{x j}}{\partial \tau_{i}}=\frac{\alpha^{2}\left[\beta n X^{\prime \prime}+(\beta-1) Y^{\prime \prime}\right]}{n X^{\prime \prime}\left(X^{\prime \prime}+Y^{\prime \prime}\right)} \gtreqless 0, \quad j \neq i .
\end{aligned}
$$

If country $i$ increases its emissions tax rate, capital in its dirty sector declines and capital in the dirty sectors of the other countries goes up. The first effect induces a reduction in pollution in country $i$, while the second effect increases pollution if pollution is transboundary $(\beta>0)$. In any case, the first effect is larger in absolute terms than the second, since total investments in the dirty sectors of all countries fall. The increase in country $i$ 's emissions tax rate therefore reduces pollution in country $i$, as shown in (15). According to (16), the effect of country $i$ 's emissions tax rate on pollution in the other countries is ambiguous. If pollution is local $(\beta=0)$, the only effect is that capital input in country $j$ 's dirty sector and, thus, emissions of this sector increase. Country $j$ then suffers from higher pollution. In the more relevant case of global pollution $(\beta=1)$, however, country $j$ also benefits from the emissions 
reduction in the dirty sector of country $i$. This effect then again dominates and leads to a reduction of pollution in country $j$. Differentiating (14) with respect to country $i$ 's green subsidy rate and using (13) yields

$$
\frac{\partial e_{j}}{\partial \sigma_{i}}=\alpha[1+\beta(n-1)] \frac{\partial k_{x j}}{\partial \sigma_{i}}=\frac{\alpha[1+\beta(n-1)]}{n\left(X^{\prime \prime}+Y^{\prime \prime}\right)}<0 .
$$

An increase in country $i$ 's green subsidy relocates capital from the dirty sectors of all countries to the clean sector of country $i$. Hence, total pollution declines in all countries, regardless of whether pollution is local or global, as shown by (17).

Households. Each country is populated by a representative household that consumes a private consumption good. ${ }^{4}$ Consumption in country $i$ is denoted by $c_{i}$ and financed by three sources of income. First, the household owns the capital endowment $\bar{k}$ and gets capital income $r \bar{k}$. Second, the household owns the firms located in its country and gets the net profits (1) and (3) as profit income. ${ }^{5}$ Third, the household in country $i$ receives a lump sum transfer that reflects the government's net tax receipts $b_{i}=\tau_{i} \alpha k_{x i}-\sigma_{i} k_{y i}$. Note that $b_{i}$ represents a lump sum payment from the household to the government if the subsidy payments are larger than the emissions tax revenues. The private budget constraint of the household in country $i$ reads

$$
c_{i}=r \bar{k}+\pi_{x i}+\pi_{y i}+b_{i}=r \bar{k}+X\left(k_{x i}\right)-r k_{x i}+Y\left(k_{y i}\right)-r k_{y i}
$$

According to (18), private consumption is financed by capital income plus the gross profits of the firms in the dirty and clean sectors.

The impact of the emissions tax on consumption is obtained by differentiating (18), taking into account $(2),(4),(7)-(9)$ and the symmetry property. This yields

$$
\begin{aligned}
& \frac{\partial c_{i}}{\partial \tau_{i}}=\alpha \tau \frac{\partial k_{x i}}{\partial \tau_{i}}-\sigma \frac{\partial k_{y i}}{\partial \tau_{i}}=\frac{\alpha^{2} \tau\left[n X^{\prime \prime}+(n-1) Y^{\prime \prime}\right]}{n X^{\prime \prime}\left(X^{\prime \prime}+Y^{\prime \prime}\right)}+\frac{\alpha \sigma}{n\left(X^{\prime \prime}+Y^{\prime \prime}\right)}, \\
& \frac{\partial c_{j}}{\partial \tau_{i}}=\alpha \tau \frac{\partial k_{x j}}{\partial \tau_{i}}-\sigma \frac{\partial k_{y j}}{\partial \tau_{i}}=-\frac{\alpha^{2} \tau Y^{\prime \prime}}{n X^{\prime \prime}\left(X^{\prime \prime}+Y^{\prime \prime}\right)}+\frac{\alpha \sigma}{n\left(X^{\prime \prime}+Y^{\prime \prime}\right)}, \quad j \neq i .
\end{aligned}
$$

\footnotetext{
${ }^{4}$ Consumption may either be interpreted as energy consumption or we may assume that energy is used in order to produce a further consumption good with a one-to-one technology. This is simplifying, of course, but taking into account a more sophisticated production structure would complicate the analysis a lot without affecting the main insights of our analysis.

${ }^{5} \mathrm{An}$ alternative interpretation is that the household in country $i$ owns a fixed second production factor like labor and that production in each sector exhibits constant returns to scale with respect to capital and labor. The remuneration of labor is then the same as the net profits in (1) and (3).
} 
Both policy instruments distort the investment decisions of firms. For positive tax and subsidy rates, capital input in the dirty sector is too low (marginal gross profits are positive), while capital input in the clean sector is too high (marginal gross profits are negative), relatively to a non-distorted economy without pollution. If in such a situation country $i$ increases its emissions tax, capital input in the dirty sector in country $i$ further decreases and capital input in the clean sector of country $i$ further increases. Both effects reduce the gross profits of the two sectors and, thus, private income and private consumption in country $i$. Formally, this follows from (19) if $\tau, \sigma>0$. In contrast, (20) and $\tau, \sigma>0$ imply that the effect of country $i$ 's emissions tax on country $j$ 's private consumption is ambiguous. The reason is that an increase in country $i$ 's emissions tax now raises capital input not only in country $j$ 's clean sector, but also in country $j$ 's dirty sector. Hence, clean investment in country $j$ becomes more distorted, indeed, but dirty investment in country $j$ moves closer to its undistorted level.

Differentiating equation (18) with respect to $\sigma_{i}$, taking into account $(2),(4),(11)-$ (13) and the symmetry properties gives

$$
\begin{aligned}
& \frac{\partial c_{i}}{\partial \sigma_{i}}=\alpha \tau \frac{\partial k_{x i}}{\partial \sigma_{i}}-\sigma \frac{\partial k_{y i}}{\partial \sigma_{i}}=\frac{\alpha \tau}{n\left(X^{\prime \prime}+Y^{\prime \prime}\right)}+\frac{\sigma\left[(n-1) X^{\prime \prime}+n Y^{\prime \prime}\right]}{n Y^{\prime \prime}\left(X^{\prime \prime}+Y^{\prime \prime}\right)}, \\
& \frac{\partial c_{j}}{\partial \sigma_{i}}=\alpha \tau \frac{\partial k_{x j}}{\partial \sigma_{i}}-\sigma \frac{\partial k_{y j}}{\partial \sigma_{i}}=\frac{\alpha \tau}{n\left(X^{\prime \prime}+Y^{\prime \prime}\right)}-\frac{\sigma X^{\prime \prime}}{n Y^{\prime \prime}\left(X^{\prime \prime}+Y^{\prime \prime}\right)}, \quad j \neq i .
\end{aligned}
$$

The above-mentioned distortions of the firms' investment decision in country $i$ are amplified by an increase in country $i$ 's green subsidy, with the consequence that private income and consumption in country $i$ falls when country $i$ raises its green subsidy, as shown in (21). The effect on private income and consumption in country $j$ is ambiguous, as shown by (22), since the increase in country $i$ 's green subsidy reduces capital input in the clean sector of country $j$ and, thus, mitigates the accompanying distortion.

Beside private consumption, the household's utility is affected by environmental pollution given by (14). Preferences of country $i$ 's household are therefore represented by the quasi-concave utility function $u_{i}=U\left(c_{i}, e_{i}\right)$ which increases with private consumption $\left(U_{c}>0\right)$ and decreases with environmental pollution $\left(U_{e}<0\right)$.

\section{Centralized (First-Best) Policy Making}

As a benchmark we consider the centralized (cooperative) economy where all policy instruments are chosen by a social planner, e.g. a supranational authority like the United Nations, who maximizes Utilitarian welfare of the households in all countries. 
It is straightforward to show that the centralized policy coincides with the first-best (Pareto) optimum. Formally, the centralized solution is obtained by maximizing $u=$ $\sum_{i=1}^{n} U\left(c_{i}, e_{i}\right)$ with respect to $\tau_{i}$ and $\sigma_{i}$. Since all countries are assumed to be identical, we focus on the symmetric solution with $\tau_{i}=\tau^{o}$ and $\sigma_{i}=\sigma^{o}$, where the superscript 'o' indicates the centralized solution. The first-order conditions then read

$$
\begin{aligned}
\frac{\partial u}{\partial \tau_{i}} & =U_{c}\left[\frac{\partial c_{i}}{\partial \tau_{i}}+(n-1) \frac{\partial c_{j}}{\partial \tau_{i}}\right]+U_{e}\left[\frac{\partial e_{i}}{\partial \tau_{i}}+(n-1) \frac{\partial e_{j}}{\partial \tau_{i}}\right]=0, \\
\frac{\partial u}{\partial \sigma_{i}} & =U_{c}\left[\frac{\partial c_{i}}{\partial \sigma_{i}}+(n-1) \frac{\partial c_{j}}{\partial \sigma_{i}}\right]+U_{e}\left[\frac{\partial e_{i}}{\partial \sigma_{i}}+(n-1) \frac{\partial e_{j}}{\partial \sigma_{i}}\right]=0,
\end{aligned}
$$

with $j \neq i$. Using (15)-(17) and (19)-(22), both (23) and (24) can be rearranged to

$$
\alpha \tau^{o}+\sigma^{o}=-\alpha[1+\beta(n-1)] \frac{U_{e}\left(c^{o}, e^{o}\right)}{U_{c}\left(c^{o}, e^{o}\right)} .
$$

From (2), (4), (14), (18), (25) and the symmetry property we immediately obtain

Proposition 1. Suppose the choice of policy instruments is centralized. Then the emissions tax rate $\tau^{o}$ and the green subsidy rate $\sigma^{o}$ satisfy (25). The centralized (firstbest) capital allocation $\left(k_{x}^{o}, k_{y}^{o}\right)$ is determined by

$$
X^{\prime}\left(k_{x}^{o}\right)=Y^{\prime}\left(k_{y}^{o}\right)-\alpha[1+\beta(n-1)] \frac{U_{e}\left(c^{o}, e^{o}\right)}{U_{c}\left(c^{o}, e^{o}\right)},
$$

with $c^{o}=X\left(k_{x}^{o}\right)+Y\left(k_{y}^{o}\right), e^{o}=\alpha[1+\beta(n-1)] k_{x}^{o}$ and $k_{x}^{o}=\bar{k}-k_{y}^{o}$.

Equation (26) characterizes the first-best capital allocation. It requires that in each country the marginal return to capital in the dirty sector $\left(X^{\prime}\right)$ equals the opportunity costs in terms of the marginal return to capital in the clean sector $\left(Y^{\prime}\right)$ plus the marginal environmental damage $\left(-\alpha[1+\beta(n-1)] U_{e} / U_{c}\right)$. For $\beta=0$ emissions in each country are local and cause damage in this country only, so the marginal damage reads $-\alpha U_{e} / U_{c}$. For $\beta=1$ we have global pollution and emissions generated in one country cause equal environmental damage in all countries, so the marginal environmental damage becomes $-\alpha n U_{e} / U_{c}$. According to (25), the first-best capital allocation is implemented by convex combinations of the emissions tax rate and the green subsidy, where the degree of internalization, $\alpha \tau+\sigma$, reflects the full marginal environmental damage.

\section{Decentralized Policy Making}

Non-Cooperative Nash Policy Game. As already mentioned in the Introduction, in the current state we do not have a centralized authority that cooperatively deter- 
mines the environmental policy of the countries. Instead, environmental policy is made to a large extent at a decentralized level. We therefore now turn to the case where each country chooses its tax and subsidy in a non-cooperative manner such as to maximize welfare of its resident. Formally, country $i$ maximizes $u_{i}=u\left(c_{i}, e_{i}\right)$ with respect to $\tau_{i}$ and $\sigma_{i}$, taking as given $\tau_{j}$ and $\sigma_{j}$ for all $j \neq i$. Hence, we consider a Nash game between $n$ countries, where each country sets two policy instruments.

We restrict attention to the symmetric equilibrium of this game. Differentiating $u\left(c_{i}, e_{i}\right)$ and taking into account $(15),(17),(19),(21)$ and the symmetry property, the first-order conditions of country $i$ 's welfare maximization can be written as

$$
\begin{aligned}
\frac{\partial u_{i}}{\partial \tau_{i}}= & U_{c} \frac{\partial c_{i}}{\partial \tau_{i}}+U_{e} \frac{\partial e_{i}}{\partial \tau_{i}} \\
=U_{c}\left(\frac{\alpha^{2} \tau\left[n X^{\prime \prime}+(n-1) Y^{\prime \prime}\right]}{n X^{\prime \prime}\left(X^{\prime \prime}+Y^{\prime \prime}\right)}+\right. & \left.\frac{\alpha \sigma}{n\left(X^{\prime \prime}+Y^{\prime \prime}\right)}\right) \\
& \quad+U_{e} \frac{\alpha^{2}\left[n X^{\prime \prime}+(1-\beta)(n-1) Y^{\prime \prime}\right]}{n X^{\prime \prime}\left(X^{\prime \prime}+Y^{\prime \prime}\right)}=0 \\
\frac{\partial u_{i}}{\partial \sigma_{i}}= & U_{c} \frac{\partial c_{i}}{\partial \sigma_{i}}+U_{e} \frac{\partial e_{i}}{\partial \sigma_{i}} \quad \\
= & U_{c}\left(\frac{\alpha \tau}{n\left(X^{\prime \prime}+Y^{\prime \prime}\right)}+\frac{\sigma\left[(n-1) X^{\prime \prime}+n Y^{\prime \prime}\right]}{n Y^{\prime \prime}\left(X^{\prime \prime}+Y^{\prime \prime}\right)}\right)+U_{e} \frac{\alpha[1+\beta(n-1)]}{n\left(X^{\prime \prime}+Y^{\prime \prime}\right)}=0
\end{aligned}
$$

These expressions determine the Nash equilibrium of the policy game. In order to highlight the role of the green subsidy, we proceed stepwise and first consider the case where the green subsidy is not available and then consider the general case where the countries may use both the emissions tax and the green subsidy.

Green subsidy not available. In this case, equation (28) becomes obsolete and we set $\sigma$ identical to zero. Let the equilibrium emissions tax rate be denoted by $\tau^{\triangleleft}$. Solving equation (27) with respect to $\tau^{\triangleleft}$ yields

$$
\tau^{\triangle}=-\frac{n X^{\prime \prime}+(1-\beta)(n-1) Y^{\prime \prime}}{n X^{\prime \prime}+(n-1) Y^{\prime \prime}} \frac{U_{e}}{U_{c}}>0 .
$$

Combining (2) and (4) with (29) and $\sigma^{\Delta}=0$ gives

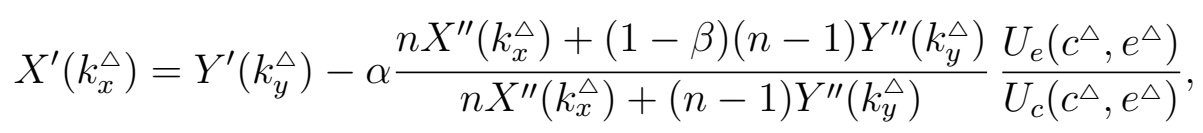

with $c^{\triangle}=X\left(k_{x}^{\triangle}\right)+Y\left(k_{y}^{\triangle}\right), e^{\triangle}=\alpha[1+\beta(n-1)] k_{x}^{\triangle}$ and $k_{x}^{\Delta}=\bar{k}-k_{y}^{\triangle}$ from (14), (18) and the symmetry property. Equation (30) determines the equilibrium capital allocation 
$\left(k_{x}^{\triangleleft}, k_{y}^{\triangleright}\right)$ in the case where the green subsidy is not at the governments' disposal. As the first-best condition (26), it equates the marginal return to capital in the dirty sector to the opportunity costs in terms of the marginal return to capital in the clean sector and a term containing the negative environmental effect $U_{e} / U_{c}$.

This latter term, however, may be different from the corresponding term in the first-best optimum. In Appendix B, we prove

Proposition 2. Suppose the choice of policy instruments is decentralized, but the green subsidy is not available to the countries. Then the equilibrium emissions tax rate $\tau^{\triangle} i s$ strictly positive and given by (29). If emissions are local $(\beta=0)$, the equilibrium capital allocation is efficient $\left(k_{x}^{\triangle}=k_{x}^{o}, k_{y}^{\Delta}=k_{y}^{o}\right)$. If emissions are transboundary $(\beta>0)$, equilibrium capital input in the dirty sector is inefficiently high $\left(k_{x}^{\Delta}>k_{x}^{o}\right)$ whereas it is inefficiently low in the clean sector $\left(k_{y}^{\triangleleft}<k_{y}^{o}\right)$.

The decentralized choice of the emissions tax rate ensures the first-best allocation, if emissions are local and cause damages only in the country where they are generated $(\beta=0)$. In the more relevant case of transboundary pollution $(\beta>0)$, in contrast, too much capital is invested in the dirty sectors and too little in the clean sectors. The rationale of this inefficiency goes back to two effects. First, each country only takes into account the externality that its dirty sector inflicts on its own residents, but it ignores the externality that its dirty sector inflicts on residents of the other countries. Second, from the point of view of the individual country the emissions tax distorts investment in the dirty sector since it leads to an outflow of capital to the other countries. Both effects induce the individual country to set the emissions tax inefficiently low, i.e. below the full marginal environmental damage. ${ }^{6}$ Hence, for the case of transboundary pollution the dirty sectors do not face the full social costs of their production and invest too much at the expense of investments in the clean sectors.

Green subsidy is available. When the green subsidy is at the governments' disposal, we have to take into account both equation (27) and equation (28). Solving these equations with respect to $\tau$ and $\sigma$ yields the equilibrium policy instruments

$$
\tau^{*}=-\frac{X^{\prime \prime}+(1-\beta) Y^{\prime \prime}}{X^{\prime \prime}+Y^{\prime \prime}} \frac{U_{e}}{U_{c}}>0, \quad \sigma^{*}=-\frac{\alpha \beta Y^{\prime \prime}}{X^{\prime \prime}+Y^{\prime \prime}} \frac{U_{e}}{U_{c}} \geq 0 .
$$

\footnotetext{
${ }^{6}$ Formally this can be seen by comparing the policy instruments in (25) and (29).
} 
where the star indicates equilibrium values when both instruments are available. Combining (2) and (4) with (31) yields

$$
X^{\prime}\left(k_{x}^{*}\right)=Y^{\prime}\left(k_{y}^{*}\right)-\alpha \frac{U_{e}\left(c^{*}, e^{*}\right)}{U_{c}\left(c^{*}, e^{*}\right)},
$$

with $c^{*}=X\left(k_{x}^{*}\right)+Y\left(k_{y}^{*}\right), e^{*}=\alpha[1+\beta(n-1)] k_{x}^{*}$ and $k_{x}^{*}=\bar{k}-k_{y}^{*}$ from (14), (18) and the symmetry property. Equation (32) determines the equilibrium capital allocation $\left(k_{x}^{*}, k_{y}^{*}\right)$ in the case where the countries choose both policy instruments. It again balances the marginal return to investment in the two sectors and a term containing the negative environmental effect $U_{e} / U_{c}$.

The environmental effect may be different from the corresponding term in the firstbest solution and, in addition, from the corresponding term in the equilibrium without the green subsidy. Comparing (32) with (30) and (26), Appendix B proves

Proposition 3. Suppose the choice of policy instruments is decentralized and both policy instruments are available to the countries.

(i) If emissions are local $(\beta=0)$, the equilibrium policy instruments are $\tau^{*}>0$ and $\sigma^{*}=0$ given by (31). The equilibrium capital allocation is efficient $\left(k_{x}^{*}=k_{x}^{o}, k_{y}^{*}=k_{y}^{o}\right)$. (ii) If emissions are transboundary $(\beta>0)$, the equilibrium policy instruments are $\tau^{*}>0$ and $\sigma^{*}>0$ given by (31). Equilibrium capital input in the dirty (clean) sector is inefficiently high (low) but lower (higher) than in the case where the green subsidy is not available $\left(k_{x}^{\triangleright}>k_{x}^{*}>k_{x}^{o}\right.$ and $\left.k_{y}^{\Delta}<k_{y}^{*}<k_{y}^{o}\right)$.

According to the first part of Proposition 3, the countries do not use the green subsidy if environmental pollution is local $(\beta=0)$. The reason is that the countries realize the first-best allocation of capital even if they are not allowed to use the green subsidy (see Proposition 2). Hence, when the green subsidy becomes available to the countries, there is no additional gain from using this instruments.

As shown in the second part of Proposition 3, things are different in the more relevant case of transboundary pollution $(\beta>0)$. In this case, each country has an incentive to mix both policy instruments. The intuition is as follows. Using the emissions tax does not only help to internalize the environmental externality, but also distorts the production decision of firms in the sense that an increase in one country's tax rate drives out capital from this country's dirty sector to other countries. As consequence profit income from the dirty sector and, thus, private consumption falls. The same is true for the green subsidy since it leads to an overaccumulation of capital in 
the clean sector. But both distortions increase overproportionally with the tax/subsidy rate. Hence, it is better for each country to reduce the emissions tax rate and introduce a positive green subsidy rate since this policy mix lowers the overall distortion of the tax/subsidy system and allows to internalize a larger part of the environmental externality. Formally, it can be shown that the emissions tax rate is lower if both policy instruments are available than if the green subsidy is not available $\left(\tau^{\triangleleft}>\tau^{*}\right)$, and that the degree of internalization is higher if both policy instruments are available than if the green subsidy is not at the governments' disposal $\left(\alpha \tau^{*}+\sigma^{*}>\tau^{\triangleleft}\right)$.

Because of the higher internalization of the environmental externality, the capital allocation is more efficient if both policy instruments are combined in comparison to the single use of the emissions tax. Investments in the dirty sectors fall and investments in the clean sectors increase when the green subsidy comes into play, even though the sectors still miss the efficient policy. Hence, the use of the green subsidy is not only beneficial for the country which employs it, but it benefits all countries by improving efficiency of the international capital allocation. The reason is that the green subsidy allocates more capital into the clean sectors, relatively to the dirty sectors. In case of transboundary pollution, this reduces emissions and increases welfare in all countries.

\section{$5 \quad$ Extensions}

Endogenous Capital Supply. Our argument in favor of green subsidies builds on the effect that the additional investments in the clean sectors come exclusively from a reduction of investments in the dirty sectors. This effect is driven by the assumption of a fixed capital supply. One may conjecture that with an endogenous capital supply the additional green investments also come from a rise in capital supply and, depending on the elasticity of capital supply, the rise may be so large that even dirty investments increase as a reaction on the use of green subsidies. However, in the present section we will show that our main results remain true if capital supply is endogenized.

For that purpose, consider a two-period version of our basic model investigated in the previous sections. The investment decisions of dirty and clean sectors remain unchanged. For notational convenience, we focus on the most relevant case of global pollution with $\beta=1 .^{7}$ The main change in model assumptions is that households now choose their savings. The household in country $i$ lives two periods. In the first period,

\footnotetext{
${ }^{7}$ It can be shown that the generalizations of results presented in this section also hold for $\beta \in[0,1[$.
} 
it disposes of an endowment $\bar{k}$ which may either be consumed in quantity $c_{1 i}$ or saved in quantity $s_{i}$. In the second period, it finances consumption $c_{2 i}$ by capital income $(1+r) s_{i}$, profit income $\pi_{x i}+\pi_{y i}$ defined in (1) and (3) and the lump-sum transfer $b_{i}=$ $\tau_{i} \alpha k_{x i}-\sigma_{i} k_{y i}$. The budget constraint of country $i$ 's household therefore reads $c_{1 i}+s_{i}=\bar{k}$ in the first period and $c_{2 i}=(1+r) s_{i}+X\left(k_{x i}\right)-r k_{x i}+Y\left(k_{y i}\right)-r k_{y i}$ in the second period. The life-time utility of country $i$ 's household is given by $u_{i}=c_{2 i}+W\left(c_{1 i}\right)+V\left(e_{i}\right)$ with $W^{\prime}>0, W^{\prime \prime}<0, V^{\prime}<0$ and $V^{\prime \prime}<0$. Maximizing life-time utility subject to the budget constraints yields the first-order condition $1+r-W^{\prime}\left(\bar{k}-s_{i}\right)=0$ which determines optimal savings $s_{i}=S(r)$ with $S^{\prime}(r)=-1 / W^{\prime \prime}>0$. The capital market equilibrium condition turns into $\sum_{i=1}^{n}\left(k_{x i}+k_{y i}\right)=n S(r)$. Hence, we now have a world capital market where the capital supply is not fixed, but dependent on the world interest rate.

In this modified model, it is straightforward to derive conditions which determine the capital allocation in centralized (first-best) and decentralized economies. Focusing on the symmetric situation, these conditions can be written in a unique way as

$$
\begin{gathered}
X^{\prime}\left(k_{x}\right)-Y^{\prime}\left(k_{y}\right)=\alpha \tau+\sigma, \\
W^{\prime}\left(\bar{k}-k_{x}-k_{y}\right)=1+Y^{\prime}\left(k_{y}\right)+\sigma .
\end{gathered}
$$

The first-best capital allocation $\left(k_{x}^{o}, k_{y}^{o}\right)$ is obtained from (33) and (34) if we set

$$
\tau=\tau^{o}=-n V^{\prime}, \quad \sigma=\sigma^{o}=0 .
$$

The equilibrium capital allocation $\left(k_{x}^{\triangleleft}, k_{y}^{\triangleleft}\right)$ in the decentralized economy without the green subsidy follows from (33) and (34) if

$$
\tau=\tau^{\triangleleft}=-\frac{n X^{\prime \prime}\left(1-S^{\prime} Y^{\prime \prime}\right)}{n X^{\prime \prime}\left(1-S^{\prime} Y^{\prime \prime}\right)+(n-1) Y^{\prime \prime}} V^{\prime}, \quad \sigma=\sigma^{\triangleleft}=0 .
$$

Finally, (33) and (34) yield the equilibrium capital allocation $\left(k_{x}^{*}, k_{y}^{*}\right)$ in the decentralized economy with the green subsidy if

$$
\begin{aligned}
& \tau=\tau^{*}=-\frac{(n-1) X^{\prime \prime}\left(X^{\prime \prime}+Y^{\prime \prime}\right)-S^{\prime} X^{\prime \prime} Y^{\prime \prime}\left[n Y^{\prime \prime}\left(1-S^{\prime} X^{\prime \prime}\right)+(2 n-1) X^{\prime \prime}\right]}{(n-1)\left(X^{\prime \prime}+Y^{\prime \prime}\right)^{2}-(2 n-1) S^{\prime} X^{\prime \prime} Y^{\prime \prime}\left(X^{\prime \prime}+Y^{\prime \prime}\right)+n\left(S^{\prime} X^{\prime \prime} Y^{\prime \prime}\right)^{2}} V^{\prime}, \\
& \sigma=\sigma^{*}=-\frac{\alpha(n-1) Y^{\prime \prime}\left(X^{\prime \prime}+Y^{\prime \prime}-S^{\prime} X^{\prime \prime} Y^{\prime \prime}\right)}{(n-1)\left(X^{\prime \prime}+Y^{\prime \prime}\right)^{2}-(2 n-1) S^{\prime} X^{\prime \prime} Y^{\prime \prime}\left(X^{\prime \prime}+Y^{\prime \prime}\right)+n\left(S^{\prime} X^{\prime \prime} Y^{\prime \prime}\right)^{2}} V^{\prime} .
\end{aligned}
$$

Note that, compared to the basic model with fixed capital supply, we now have the additional condition (34) which endogenously determines savings and capital supply.

Taking into account of this additional condition, we can prove ${ }^{8}$

\footnotetext{
${ }^{8}$ The proof of Proposition 4 and Proposition 5 is contained in an supplement appendix which can be obtained from the authors upon request.
} 
Proposition 4. Suppose capital supply is endogenous. Then the results obtained for fixed capital supply in Proposition 2 and 3 remain unchanged.

Even with endogenous capital supply, the green subsidy is beneficial for all countries since it reduces investment and, thus, emissions of dirty sectors. The rationale is as follows. As with fixed capital supply, (33) requires that the first-best policy (35) balances the marginal returns to capital in the two sectors and the marginal environmental damage. Equation (34) shows that in the first-best optimum capital supply is increased up to the point where the intertemporal rate of substitution equals the rate of transformation. In a decentralized economy without the green subsidy, (33) and (36) imply that the emissions tax is inefficiently low $\left(\alpha \tau^{\triangleleft}<\alpha \tau^{o}\right)$, causing overinvestment in dirty sectors and underinvestment in green sectors. The savings decision is undistorted due to (34) and $\sigma^{\Delta}=0$. When the green subsidy becomes available, the degree of internalization increases $\left(\alpha \tau^{*}+\sigma^{*}>\alpha \tau^{\Delta}\right)$, so dirty investments ceteris paribus fall in favor of green investment. In addition, (34) and $\sigma^{*}>0$ imply that the green subsidy increases capital supply and thereby ceteris paribus exerts additional positive effects on green and dirty investment. These effects are new, but they do not reverse our results. The positive effect on dirty investments is overcompensated by the fall in dirty investments due to higher internalization, and the additional positive effect on green investments will not lead to higher green investments than in the first-best. Put differently, in equilibrium the countries set their green subsidy rates such that capital is sufficiently inelastic in order to preserve the beneficial role of the green subsidy.

Cap-and-Trade Systems. So far we have considered emissions taxes as the primary environmental policy instrument. Many countries have such taxes, indeed, but there is also a widespread use of emissions trading schemes or so-called cap-and-trade systems. This observation raises the question whether our argument in favor of green subsidies prevails when countries employ cap-and-trade systems instead of emissions taxes. If all countries have emissions trading schemes, our argument for green subsidies breaks down, since the caps fix total emissions and, thus, there is no longer the option to reduce world-wide emissions by lowering dirty investment with the help of green subsidies. However, in practice not all countries have established cap-and-trade systems. There are even countries that do not impose environmental policy at all. For such a case we now show that the argument in favor of green subsidies basically prevails.

For sake of illustration consider a simplified version of our basic model with only 
two countries. The 'green' country may implement a cap-and-trade system and impose a green subsidy. The 'dirty' country does not impose policy measures at all. For notational convenience, we drop the country indices $i$ and $j$ and indicate variables of the dirty country by a hat. The cap-and-trade system in the green country is represented by the restriction $\alpha k_{x} \leq q$ where $q$ is the cap. Let the permit price be denoted by $p$. The first-order conditions for profit maximization in the green country read $X^{\prime}\left(k_{x}\right)=r+\alpha p$ and $Y^{\prime}\left(k_{y}\right)=r-\sigma$. In the dirty country we obtain $X^{\prime}\left(\hat{k}_{x}\right)=r$ and $Y^{\prime}\left(\hat{k}_{y}\right)=r$. We again focus on the most relevant case of $\beta=1$.

In a uniform way, the conditions which determine the capital allocation in centralized and decentralized economies can be written as $k_{x}+k_{y}+\hat{k}_{x}+\hat{k}_{y}=2 \bar{k}$ and

$$
\begin{aligned}
& X^{\prime}\left(k_{x}\right)-Y^{\prime}\left(k_{y}\right)=\theta, \\
& X^{\prime}\left(\hat{k}_{x}\right)-Y^{\prime}\left(\hat{k}_{y}\right)=\hat{\theta}, \\
& Y^{\prime}\left(k_{y}\right)-Y^{\prime}\left(\hat{k}_{y}\right)=\gamma .
\end{aligned}
$$

The first-best capital allocation $\left(k_{x}^{o}, k_{y}^{o}, \hat{k}_{x}^{o}, \hat{k}_{y}^{o}\right)$ follows from these conditions if we set

$$
\theta=\hat{\theta}=\alpha p^{o}+\sigma^{o}=-2 \alpha \frac{U_{e}}{U_{c}}, \quad \gamma=0 .
$$

The decentralized allocation without the green subsidy, $\left(k_{x}^{\Delta}, k_{y}^{\Delta}, \hat{k}_{x}^{\Delta}, \hat{k}_{y}^{\triangleleft}\right)$, is obtained if

$$
\theta=\alpha p^{\Delta}=-\alpha \frac{\hat{X}^{\prime \prime}\left(Y^{\prime \prime}+\hat{Y}^{\prime}\right)}{\hat{X}^{\prime \prime} \hat{Y}^{\prime \prime}+Y^{\prime \prime}\left(\hat{X}^{\prime \prime}+\hat{Y}^{\prime \prime}\right)} \frac{U_{e}}{U_{c}}+\frac{\left(\bar{k}-k_{x}^{\Delta}-k_{y}^{\triangle}\right) Y^{\prime \prime} \hat{X}^{\prime \prime} \hat{Y}^{\prime \prime}}{\hat{X}^{\prime \prime} \hat{Y}^{\prime \prime}+Y^{\prime \prime}\left(\hat{X}^{\prime \prime}+\hat{Y}^{\prime \prime}\right)}, \quad \hat{\theta}=\gamma=0 .
$$

For the decentralized allocation with the green subsidy, $\left(k_{x}^{*}, k_{y}^{*}, \hat{k}_{x}^{*}, \hat{k}_{y}^{*}\right)$, we have to set

$$
\theta=\alpha p^{*}+\sigma^{*}=-\alpha \frac{U_{e}}{U_{c}}, \hat{\theta}=0, \gamma=-\sigma^{*}=\alpha \frac{\hat{Y}^{\prime \prime}}{\hat{X}^{\prime \prime}+\hat{Y}^{\prime \prime}} \frac{U_{e}}{U_{c}}+\frac{\left(\bar{k}-k_{x}^{*}-k_{y}^{*}\right) \hat{X}^{\prime \prime} \hat{Y}^{\prime \prime}}{\hat{X}^{\prime \prime}+\hat{Y}^{\prime \prime}} .
$$

Observe that the green country's incentive to impose a green subsidy is even stronger than in the basic model. This can be seen by comparing $\sigma^{*}$ from (31) with $\sigma^{*}$ from (44) and noting that $\bar{k}>k_{x}^{*}+k_{y}^{*}$. The reason is that due to its environmental policy the green country exports capital and, thus, wants to increase capital income $r\left(\bar{k}-k_{x}^{*}-k_{y}^{*}\right)$ by raising the interest rate through an increase in the green subsidy rate $(\partial r / \partial \sigma>0)$. Due to symmetry, this terms of trade effect does not appear in the basic model.

Unfortunately, the asymmetry of the capital allocation renders the comparison of the different settings untractable in general. However, for quadratic production functions and linear utility functions we can show 
Proposition 5. Suppose $n=2$ and one country has at its disposal a cap-and-trade system and a green subsidy, while the other country does not impose environmental policy at all. Moreover, assume that $X\left(k_{x}\right)=a_{x} k_{x}-b_{x} k_{x}^{2} / 2, Y\left(k_{y}\right)=a_{y} k_{y}-b_{y} k_{y}^{2} / 2$ and $U(c, e)=c-f e$ with $a_{x}, a_{y}, b_{x}, b_{y}, f>0$. Then the results obtained in Proposition 2 and 3 remain true, except that the dirty country's welfare may be decreased by the green subsidy because $\hat{k}_{y}^{*}<\hat{k}_{y}^{\Delta}<\hat{k}_{y}^{o}$.

According to Proposition 5 our basic argument in favor of green subsidies remains true even in the presence of cap-and-trade systems, at least from the green country's point of view. The dirty country may loose by the use of the green subsidy. The rationale of these insights is as follows. Without the green subsidy, the green country chooses an inefficiently high cap because it ignores the externality on other countries, the positive permit price leads to an outflow of capital to the dirty country and a higher cap causes the same terms of trade effect as the one described above for the green subsidy. It is then beneficial for the green country to use the green subsidy in order to reduce the overall distortion of its policy and to influence the terms of trade in its favor. This brings back capital to the green country and reduces world-wide emissions since dirty investments in the dirty country is reduced, even though dirty investments in the green country is unaffected due to the cap. The reduction in pollution and the relocation of capital unambiguously increases welfare of the green country. The reduction in pollution also benefits the dirty country, but overall welfare of this country may be lowered, since the additional green investments in the green country also comes from the green sector of the dirty country $\left(\hat{k}_{y}^{*}<\hat{k}_{y}^{\triangleleft}\right)$.

\section{Conclusion}

Subsidies on renewable energy may reduce the overall distortion of tax-subsidies schemes. Therefore, in a decentralized world countries may face the incentive to use such green subsidies in addition to emissions taxes or emissions trading schemes. Green subsidies may then be beneficial not only for the country imposing the subsidy, but also for the other countries since the subsidies relocate investments from dirty energy sectors into renewable energy sectors and, thus, reduce world-wide pollution and mitigate the consequences of climate change. This argument in favor of green subsidies was made in the present paper by using a multi-country model with mobile capital and decentralized environmental policy making. It turned out to be robust against certain variations in 
the model assumption such as, for example, endogenous capital supply and the use of cap-and-trade systems under asymmetric policy choices.

Our argument in favor of green subsidies may be seen as a possible economic justification for the widespread use of subsidies on renewable energy production in practice. Of course, the advantage of green subsidies derived in our framework has to be balanced against possible drawbacks which renewable energy production doubtlessly has, for example, the drawback that avoiding one ton of carbon dioxide by renewable energy is usually more expensive than avoiding this ton by other backstop technologies. Whether our argument is important enough to compensate possible drawbacks of renewable energy production cannot be answered by our theoretical model. It is an empirical question and therefore left for future research.

\section{Appendix}

A. Derivation of (6) - (13). Totally differentiating (2), (4) and (5) yields

$$
\begin{gathered}
\mathrm{d} k_{x i}=\frac{\mathrm{d} r+\alpha \mathrm{d} \tau_{i}}{X_{i}^{\prime \prime}}, \quad \mathrm{d} k_{y i}=\frac{\mathrm{d} r-\mathrm{d} \sigma_{i}}{Y_{i}^{\prime \prime}}, \\
\sum_{i=1}^{n}\left(\mathrm{~d} k_{x i}+\mathrm{d} k_{y i}\right)=0,
\end{gathered}
$$

with $X_{i}^{\prime \prime}:=X^{\prime \prime}\left(k_{x i}\right)$ and $Y_{i}^{\prime \prime}:=Y^{\prime \prime}\left(k_{y i}\right)$. Inserting (A1) into (A2) and solving with respect to $\mathrm{d} r$, we obtain

$$
\mathrm{d} r=\left(\sum_{i=1}^{n} \frac{\mathrm{d} \sigma_{i}}{Y_{i}^{\prime \prime}}-\sum_{i=1}^{n} \frac{\alpha \mathrm{d} \tau_{i}}{X_{i}^{\prime \prime}}\right) / \sum_{i=1}^{n} \frac{X_{i}^{\prime \prime}+Y_{i}^{\prime \prime}}{X_{i}^{\prime \prime} Y_{i}^{\prime \prime}} .
$$

Setting $\mathrm{d} \tau_{j}=0$ for $j \neq i, \mathrm{~d} \sigma_{j}=0$ for all $j$ and applying the symmetry property in (A3) yields (6). Inserting back into (A1) proves (7)-(9). Using $\mathrm{d} \sigma_{j}=0$ for $j \neq i, \mathrm{~d} \tau_{j}=0$ for all $j$ and symmetry in (A3), we obtain (10). Inserting into (A1) proves (11)-(13).

B. Proof of Proposition 2 and 3. It will be helpful to use the definitions

$$
\begin{aligned}
F(k) & :=X^{\prime}(k)-Y^{\prime}(\bar{k}-k), \\
G(k) & :=-\alpha[1+\beta(n-1)] \frac{U_{e}\{X(k)+Y(\bar{k}-k), \alpha[1+\beta(n-1)] k\}}{U_{c}\{X(k)+Y(\bar{k}-k), \alpha[1+\beta(n-1)] k\}}>0, \\
H(k) & :=\frac{\alpha \beta n(n-1)\left[X^{\prime \prime}(k)+Y^{\prime \prime}(\bar{k}-k)\right]}{n X^{\prime \prime}(k)+(n-1) Y^{\prime \prime}(\bar{k}-k)} \frac{U_{e}\{X(k)+Y(\bar{k}-k), \alpha[1+\beta(n-1)] k\}}{U_{c}\{X(k)+Y(\bar{k}-k), \alpha[1+\beta(n-1)] k\}} \leq 0, \\
I(k) & :=-\frac{\alpha \beta(n-1) Y^{\prime \prime}(\bar{k}-k)}{n X^{\prime \prime}(k)+(n-1) Y^{\prime \prime}(\bar{k}-k)} \frac{U_{e}\{X(k)+Y(\bar{k}-k), \alpha[1+\beta(n-1)] k\}}{U_{c}\{X(k)+Y(\bar{k}-k), \alpha[1+\beta(n-1)] k\}} \geq 0 .
\end{aligned}
$$


Condition (26) for the first-best capital allocation and conditions (30) and (32) for the capital allocation in the decentralized economy can then be rewritten as

$$
\begin{aligned}
& F\left(k_{x}^{o}\right)=G\left(k_{x}^{o}\right), \\
& F\left(k_{x}^{\triangleright}\right)=G\left(k_{x}^{\triangleright}\right)+H\left(k_{x}^{\triangleright}\right), \\
& F\left(k_{x}^{*}\right)=G\left(k_{x}^{*}\right)+H\left(k_{x}^{*}\right)+I\left(k_{x}^{*}\right) .
\end{aligned}
$$

For $\beta=0$, we obtain $H\left(k_{x}^{\triangle}\right)=0$ and, thus, (B1) and (B2) imply $k_{x}^{\Delta}=k_{x}^{o}$. From $k_{x}^{\Delta}+k_{y}^{\Delta}=\bar{k}$ and $k_{x}^{o}+k_{y}^{o}=\bar{k}$ it follows $k_{y}^{\Delta}=k_{y}^{o}$. If $\beta>0$, in contrast, $H\left(k_{x}^{\triangle}\right)<0$ and (B2) yields $F\left(k_{x}^{\triangle}\right)<G\left(k_{x}^{\triangleright}\right) . F^{\prime}(k)=X^{\prime \prime}(k)+Y^{\prime \prime}(\bar{k}-k)<0$ then implies $k_{x}^{\Delta}>k_{x}^{o}$ and $k_{y}^{\triangleleft}<k_{y}^{o}$. This completes the proof of Proposition 2 .

In order to prove Proposition 3, consider first the case $\beta=0$. We then obtain $H\left(k_{x}^{*}\right)=I\left(k_{x}^{*}\right)=0$. Comparing (B1) and (B3) yields $k_{x}^{*}=k_{x}^{o}$ and $k_{y}^{*}=k_{y}^{o}$. For $\beta>0$, $I\left(k_{x}^{*}\right)>0$ and, thus, (B3) implies $F\left(k_{x}^{*}\right)>G\left(k_{x}^{*}\right)+H\left(k_{x}^{*}\right)$. Comparing with (B2) yields $k_{x}^{*}<k_{x}^{\triangle}$ and $k_{y}^{*}>k_{y}^{\triangle}$. Finally, note that $H\left(k_{x}^{*}\right)+I\left(k_{x}^{*}\right)=\alpha \beta(n-1) U_{e}(\cdot) / U_{c}(\cdot)<0$ if $\beta>0$. Hence, (B3) implies $F\left(k_{x}^{*}\right)<G\left(k_{x}^{*}\right)$. Comparing with (B1), it follows $k_{x}^{*}>k_{x}^{o}$ and $k_{y}^{*}<k_{y}^{o}$. This completes the proof of Proposition 3 .

\section{References}

Bläsi, A. and T. Requate (2007), Subsidies for wind power: surfing down the learning curve?, CAU Economic Working Paper 2007-28, Kiel.

Chao, C.-C. and E.S.H. Yu (1997), International capital competition and environmental standards, Southern Economic Journal 64, 531-541.

Eichner, T. and R. Pethig (2009), Efficient management of insecure fossil fuel imports through taxing (!) domestic green energy?, Discussion Paper No. 138-09, University of Siegen.

Eichner, T. and R. Pethig (2010), International carbon emissions trading and strategic incentives to subsidize green energy, Discussion Paper No. 142-10, University of Siegen.

Fischer, C. and R.G. Newell (2008), Environmental and technology policies for climate change mitigation, Journal of Environmental Economics and Management 55, 142-162.

Hoel, M. (1997), Environmental policy with endogenous plant location, Scandinavian Journal of Economics 99, 241-259.

Johnstone, N. (2003), The use of tradable permits in combination with other environmental policy instruments. Report ENV/EPOC/WPNEP(2002)28/Final, OECD, Paris. 
Lehmann, P. (2009), Climate policies with pollution externalities and learning spillovers. UFZ discussion paper, Leipzig.

Markusen, J.E., Morey, E.R. and N.D. Olewiler (1993), Environmental policy when market structure and plant locations are endogenous, Journal of Environmental Economics and Management 24, $69-86$.

Markusen, J.E., Morey, E.R. and N.D. Olewiler (1995), Competition in regional environmental policy when plant locations are endogenous, Journal of Public Economics 56, 55-77.

Motta, M. and J.-F. Thisse (1994), Does environmental dumping lead to delocation?, European Economic Review 38, 563-576.

Oates, W.E. and R.M. Schwab (1988), Economic competition among jurisdictions: Efficiency enhancing or distortion inducing, Journal of Public Economics 35, 333-354.

Ogawa, H. and D.E. Wildasin (2009), Think locally, act locally: Spillovers, spillbacks, and efficient decentralized policymaking, American Economic Review 99, 1206-1217.

Ulph, A. and L. Valentini (2001), Is environmental dumping greater when plants are footlose?, Scandinavian Journal of Economics 103, 673-688.

Wilson, J.D. (1986), A theory of interregional tax competition, Journal of Urban Economics 19, 296-315.

Wilson, J.D. (1999), Theories of tax competition, National Tax Journal 52, 296-304.

Wilson, J.D. and D. Wildasin (2004), Theories of tax competition: bane or boon, Journal of Public Economics 88, 1065-1091.

Zodrow, G. and P. Mieszkowski (1986), Pigou, Tibout, property taxation and the underprovision of public goods, Journal of Urban Economics 19, 356-370. 


\section{Supplement Appendix (not to be published)}

C. Proof of Proposition 4. We first conduct a comparative static analysis of the capital market equilibrium. With endogenous savings this equilibrium is determined by (2), (4) and $\sum_{i=1}^{n}\left(k_{x i}+k_{y i}\right)=n S(r)$. Using the same procedure as in Appendix A, the effects of country $i$ ' emissions tax rate turns out to be

$$
\begin{aligned}
\frac{\partial r}{\partial \tau_{i}} & =-\frac{\alpha Y^{\prime \prime}}{n\left(X^{\prime \prime}+Y^{\prime \prime}-S^{\prime} X^{\prime \prime} Y^{\prime \prime}\right)}<0, \\
\frac{\partial k_{x i}}{\partial \tau_{i}} & =\frac{\alpha\left[n X^{\prime \prime}+(n-1) Y^{\prime \prime}-n S^{\prime} X^{\prime \prime} Y^{\prime \prime}\right]}{n X^{\prime \prime}\left(X^{\prime \prime}+Y^{\prime \prime}-S^{\prime} X^{\prime \prime} Y^{\prime \prime}\right)}<0, \\
\frac{\partial k_{x j}}{\partial \tau_{i}} & =-\frac{\alpha Y^{\prime \prime}}{n X^{\prime \prime}\left(X^{\prime \prime}+Y^{\prime \prime}-S^{\prime} X^{\prime \prime} Y^{\prime \prime}\right)}>0, \quad j \neq i, \\
\frac{\partial k_{y j}}{\partial \tau_{i}} & =-\frac{\alpha}{n\left(X^{\prime \prime}+Y^{\prime \prime}-S^{\prime} X^{\prime \prime} Y^{\prime \prime}\right)}>0 .
\end{aligned}
$$

The effects of country $i$ ' green subsidy rate are

$$
\begin{aligned}
\frac{\partial r}{\partial \sigma_{i}} & =\frac{X^{\prime \prime}}{n\left(X^{\prime \prime}+Y^{\prime \prime}-S^{\prime} X^{\prime \prime} Y^{\prime \prime}\right)}>0, \\
\frac{\partial k_{y i}}{\partial \sigma_{i}} & =-\frac{(n-1) X^{\prime \prime}+n Y^{\prime \prime}-n S^{\prime} X^{\prime \prime} Y^{\prime \prime}}{n Y^{\prime \prime}\left(X^{\prime \prime}+Y^{\prime \prime}-S^{\prime} X^{\prime \prime} Y^{\prime \prime}\right)}>0, \\
\frac{\partial k_{y j}}{\partial \sigma_{i}} & =\frac{X^{\prime \prime}}{n Y^{\prime \prime}\left(X^{\prime \prime}+Y^{\prime \prime}-S^{\prime} X^{\prime \prime} Y^{\prime \prime}\right)}<0, \quad j \neq i, \\
\frac{\partial k_{x j}}{\partial \sigma_{i}} & =\frac{1}{n\left(X^{\prime \prime}+Y^{\prime \prime}-S^{\prime} X^{\prime \prime} Y^{\prime \prime}\right)}<0 .
\end{aligned}
$$

Using (14) and the assumption $\beta=1$ yields the effects on pollution

$$
\begin{aligned}
& \frac{\partial e_{j}}{\partial \tau_{i}}=\alpha \frac{\partial k_{x i}}{\partial \tau_{i}}+\alpha(n-1) \frac{\partial k_{x j}}{\partial \tau_{i}}=\frac{\alpha^{2}\left(n X^{\prime \prime}-n S^{\prime} X^{\prime \prime} Y^{\prime \prime}\right)}{n X^{\prime \prime}\left(X^{\prime \prime}+Y^{\prime \prime}-S^{\prime} X^{\prime \prime} Y^{\prime \prime}\right)}<0, \\
& \frac{\partial e_{j}}{\partial \sigma_{i}}=\alpha n \frac{\partial k_{x j}}{\partial \sigma_{i}}=\frac{\alpha n}{n\left(X^{\prime \prime}+Y^{\prime \prime}-S^{\prime} X^{\prime \prime} Y^{\prime \prime}\right)}<0 .
\end{aligned}
$$

Defining private utility as $w_{i}:=u_{i}-V\left(e_{i}\right)=(1+r) S(r)+X\left(k_{x i}\right)-r k_{x i}+Y\left(k_{y i}\right)-$ $r k_{y i}+W[\bar{k}-S(r)]$, applying the envelope theorem and using the symmetry property $k_{x i}+k_{y i}=S(r)$ gives

$$
\begin{aligned}
\frac{\partial w_{i}}{\partial \tau_{i}} & =\frac{\alpha^{2} \tau\left[n X^{\prime \prime}+(n-1) Y^{\prime \prime}-n S^{\prime} X^{\prime \prime} Y^{\prime \prime}\right]}{n X^{\prime \prime}\left(X^{\prime \prime}+Y^{\prime \prime}-S^{\prime} X^{\prime \prime} Y^{\prime \prime}\right)}+\frac{\alpha \sigma}{n\left(X^{\prime \prime}+Y^{\prime \prime}-S^{\prime} X^{\prime \prime} Y^{\prime \prime}\right)}, \\
\frac{\partial w_{j}}{\partial \tau_{i}} & =-\frac{\alpha^{2} \tau Y^{\prime \prime}}{n X^{\prime \prime}\left(X^{\prime \prime}+Y^{\prime \prime}-S^{\prime} X^{\prime \prime} Y^{\prime \prime}\right)}+\frac{\alpha \sigma}{n\left(X^{\prime \prime}+Y^{\prime \prime}-S^{\prime} X^{\prime \prime} Y^{\prime \prime}\right)}, \quad j \neq i .
\end{aligned}
$$


and

$$
\begin{aligned}
& \frac{\partial w_{i}}{\partial \sigma_{i}}=\frac{\alpha \tau}{n\left(X^{\prime \prime}+Y^{\prime \prime}-S^{\prime} X^{\prime \prime} Y^{\prime \prime}\right)}+\frac{\sigma\left[(n-1) X^{\prime \prime}+n Y^{\prime \prime}-n S^{\prime} X^{\prime \prime} Y^{\prime \prime}\right]}{n Y^{\prime \prime}\left(X^{\prime \prime}+Y^{\prime \prime}-S^{\prime} X^{\prime \prime} Y^{\prime \prime}\right)}, \\
& \frac{\partial w_{j}}{\partial \sigma_{i}}=\frac{\alpha \tau}{n\left(X^{\prime \prime}+Y^{\prime \prime}-S^{\prime} X^{\prime \prime} Y^{\prime \prime}\right)}-\frac{\sigma X^{\prime \prime}}{n Y^{\prime \prime}\left(X^{\prime \prime}+Y^{\prime \prime}-S^{\prime} X^{\prime \prime} Y^{\prime \prime}\right)}, \quad j \neq i .
\end{aligned}
$$

Overall, we obtain exactly the same comparative static results as in the basic model, except for the additional terms containing $S^{\prime}$ which, however, do not change the signs of the comparative static results.

Combining (4) with (2) and the optimal savings condition yields

$$
\begin{gathered}
X^{\prime}\left(k_{x}\right)-Y^{\prime}\left(k_{y}\right)=\alpha \tau+\sigma, \\
W^{\prime}\left(\bar{k}-k_{x}-k_{y}\right)=1+Y^{\prime}\left(k_{y}\right)+\sigma .
\end{gathered}
$$

These two conditions are the same as (33) and (34) in the main text. They determine the capital allocation $\left(k_{x}, k_{y}\right)$ as function of the policy instruments $(\tau, \sigma)$. Hence, for the centralized (first-best) policy instruments we obtain the first-best capital allocation, whereas for the policy instruments chosen in a decentralized economy we get the equilibrium capital allocation, either for the case with or without the green subsidy. In the following we determine the policy instruments in the different institutional settings and then compare the corresponding capital allocations.

Let us start with the centralized (first-best) policy $\left(\tau^{o}, \sigma^{o}\right)$. This policy follows from maximizing $u=\sum_{i=1}^{n} u_{i}$ with respect to $\tau_{i}$ and $\sigma_{i}$ and applying the symmetry assumption. The first-order conditions are

$$
\begin{aligned}
\frac{\partial u}{\partial \tau_{i}} & =\frac{\partial w_{i}}{\partial \tau_{i}}+(n-1) \frac{\partial w_{j}}{\partial \tau_{i}}+V^{\prime}\left[\frac{\partial e_{i}}{\partial \tau_{i}}+(n-1) \frac{\partial e_{j}}{\partial \tau_{i}}\right]=0, \\
\frac{\partial u}{\partial \sigma_{i}} & =\frac{\partial w_{i}}{\partial \sigma_{i}}+(n-1) \frac{\partial w_{j}}{\partial \sigma_{i}}+V^{\prime}\left[\frac{\partial e_{i}}{\partial \sigma_{i}}+(n-1) \frac{\partial e_{j}}{\partial \sigma_{i}}\right]=0
\end{aligned}
$$

with $j \neq i$. Using $(\mathrm{C} 9)-(\mathrm{C} 10)$ and $(\mathrm{C} 11)-(\mathrm{C} 14)$, it is straightforward to show that (C17) and (C18) become

$$
\alpha\left(1-S^{\prime} Y^{\prime \prime}\right)\left(\tau^{o}+n V^{\prime}\right)+\sigma^{o}=0, \quad \alpha\left(\tau^{o}+n V^{\prime}\right)+\left(1-S^{\prime} X^{\prime \prime}\right) \sigma^{o}=0,
$$

from which we obtain $\tau^{o}=-n V^{\prime}$ and $\sigma^{o}=0$, as stated in (35).

In the decentralized economy, country $i$ maximizes $u_{i}$ with respect to $\tau_{i}$ and $\sigma_{i}$. Using (C9), (C10), (C11), (C13) and the symmetry property, the first-order conditions 
of this welfare maximization problem can be written as

$$
\begin{aligned}
\frac{\partial u_{i}}{\partial \tau_{i}}= & \frac{\partial w_{i}}{\partial \tau_{i}}+V^{\prime} \frac{\partial e_{i}}{\partial \tau_{i}} \\
= & \frac{\alpha^{2} \tau\left[n X^{\prime \prime}+(n-1) Y^{\prime \prime}-n S^{\prime} X^{\prime \prime} Y^{\prime \prime}\right]}{n X^{\prime \prime}\left(X^{\prime \prime}+Y^{\prime \prime}-S^{\prime} X^{\prime \prime} Y^{\prime \prime}\right)}+\frac{\alpha \sigma}{n\left(X^{\prime \prime}+Y^{\prime \prime}-S^{\prime} X^{\prime \prime} Y^{\prime \prime}\right)} \\
& +V^{\prime} \frac{\alpha^{2}\left(n X^{\prime \prime}-n S^{\prime} X^{\prime \prime} Y^{\prime \prime}\right)}{n X^{\prime \prime}\left(X^{\prime \prime}+Y^{\prime \prime}-S^{\prime} X^{\prime \prime} Y^{\prime \prime}\right)}=0, \\
\frac{\partial u_{i}}{\partial \sigma_{i}}= & \frac{\partial w_{i}}{\partial \sigma_{i}}+V^{\prime} \frac{\partial e_{i}}{\partial \sigma_{i}} \\
= & \frac{\alpha \tau}{n\left(X^{\prime \prime}+Y^{\prime \prime}-S^{\prime} X^{\prime \prime} Y^{\prime \prime}\right)}+\frac{\sigma\left[(n-1) X^{\prime \prime}+n Y^{\prime \prime}-n S^{\prime} X^{\prime \prime} Y^{\prime \prime}\right]}{n Y^{\prime \prime}\left(X^{\prime \prime}+Y^{\prime \prime}-S^{\prime} X^{\prime \prime} Y^{\prime \prime}\right)} \\
+V^{\prime} \frac{\alpha}{X^{\prime \prime}+Y^{\prime \prime}-S^{\prime} X^{\prime \prime} Y^{\prime \prime}} & =0 .
\end{aligned}
$$

If the green subsidy is not available, equation (C21) becomes obsolete and solving equation (C20) yields $\tau^{\triangle}$ given in equation (36). If the green subsidy is available, solving equations (C20) and (C21) yields $\tau^{*}$ and $\sigma^{*}$ in equations (37) and (38).

In order to compare the capital allocation under the different settings, define

$$
\begin{gathered}
\theta^{o}:=\alpha \tau^{o}+\sigma^{o}=G, \quad \theta^{\triangle}:=\alpha \tau^{\triangle}+\sigma^{\triangle}=G+H, \\
\theta^{*}:=\alpha \tau^{*}+\sigma^{*}=G+H+I, \quad \sigma^{*}=J,
\end{gathered}
$$

with

$$
\begin{aligned}
G & :=-\alpha n V^{\prime}>0 \\
H & :=\frac{\alpha n(n-1)\left(X^{\prime \prime}+Y^{\prime \prime}-S^{\prime} X^{\prime \prime} Y^{\prime \prime}\right)}{n X^{\prime \prime}+(n-1) Y^{\prime \prime}-n S^{\prime} X^{\prime \prime} Y^{\prime \prime}} V^{\prime}<0, \\
I & :=-\frac{\alpha(n-1) Y^{\prime \prime}}{n X^{\prime \prime}+(n-1) Y^{\prime \prime}-n S^{\prime} X^{\prime \prime} Y^{\prime \prime}} V^{\prime}>0, \\
J & :=-\frac{\alpha(n-1) Y^{\prime \prime}\left(X^{\prime \prime}+Y^{\prime \prime}-S^{\prime} X^{\prime \prime} Y^{\prime \prime}\right)}{(n-1)\left(X^{\prime \prime}+Y^{\prime \prime}\right)^{2}-(2 n-1) S^{\prime} X^{\prime \prime} Y^{\prime \prime}\left(X^{\prime \prime}+Y^{\prime \prime}\right)+n\left(S^{\prime} X^{\prime \prime} Y^{\prime \prime}\right)^{2}} V^{\prime}>0 .
\end{aligned}
$$

Note that $H+I=\alpha(n-1) V^{\prime}<0$, so $\theta^{o}>\theta^{*}>\theta^{\triangle}$ and $\sigma^{*}>0=\sigma^{o}=\sigma^{\triangle}$. A comparative static analysis of $(\mathrm{C} 15)$ and $(\mathrm{C} 16)$ with respect to $\theta:=\alpha \tau+\sigma$ and $\sigma$ yields

$$
\begin{array}{ll}
\frac{\partial k_{x}}{\partial \theta}=\frac{1-S^{\prime} Y^{\prime \prime}}{X^{\prime \prime}+Y^{\prime \prime}-S^{\prime} X^{\prime \prime} Y^{\prime \prime}}<0, & \frac{\partial k_{y}}{\partial \theta}=-\frac{1}{X^{\prime \prime}+Y^{\prime \prime}-S^{\prime} X^{\prime \prime} Y^{\prime \prime}}>0 \\
\frac{\partial k_{x}}{\partial \sigma}=\frac{S^{\prime} Y^{\prime \prime}}{X^{\prime \prime}+Y^{\prime \prime}-S^{\prime} X^{\prime \prime} Y^{\prime \prime}}>0, & \frac{\partial k_{y}}{\partial \sigma}=\frac{S^{\prime} X^{\prime \prime}}{X^{\prime \prime}+Y^{\prime \prime}-S^{\prime} X^{\prime \prime} Y^{\prime \prime}}>0
\end{array}
$$


where we used $S^{\prime}=-1 / W^{\prime \prime}$. If we go from the first-best policy to the decentralized policy without the green subsidy, then $\theta$ falls $\left(\theta^{\circ}>\theta^{\triangle}\right)$ and $\sigma$ remains constant $\left(\sigma^{o}=\right.$ $\left.\sigma^{\triangle}\right)$. Hence, (C24) implies $k_{x}^{o}<k_{x}^{\Delta}$ and $k_{y}^{o}>k_{y}^{\triangle}$, which is the same result as obtained in Proposition 2 for fixed capital supply. The transition from the decentralized policy without the green subsidy to the decentralized policy with the subsidy is associated with an increase in $\theta$ by $I$ ( since $\mathrm{d} \theta=\theta^{*}-\theta^{\triangle}=I>0$ ) and with an increase in $\sigma$ by $J$ (since $\mathrm{d} \sigma=\sigma^{*}-\sigma^{\triangle}=J>0$ ). Equation (C24) and (C25) imply $k_{y}^{\Delta}<k_{y}^{*}$. With the help of $(\mathrm{C} 24),(\mathrm{C} 25)$ and the definition of $I$ and $J$, the change in $k_{x}$ reads

$$
\mathrm{d} k_{x}=\frac{\partial k_{x}}{\partial \theta} \mathrm{d} \theta+\frac{\partial k_{x}}{\partial \sigma} \mathrm{d} \sigma=-\frac{\alpha(n-1)^{2} Y^{\prime \prime}\left(X^{\prime \prime}+Y^{\prime \prime}-S^{\prime} X^{\prime \prime} Y^{\prime \prime}\right)^{2}}{z_{1} z_{2} z_{3}} V^{\prime}<0,
$$

with $z_{1}:=X^{\prime \prime}+Y^{\prime \prime}-S^{\prime} X^{\prime \prime} Y^{\prime \prime}<0, z_{2}:=n X^{\prime \prime}+(n-1) Y^{\prime \prime}-n S^{\prime} X^{\prime \prime} Y^{\prime \prime}<0$ and $z_{3}:=(n-1)\left(X^{\prime \prime}+Y^{\prime \prime}\right)^{2}-(2 n-1) S^{\prime} X^{\prime \prime} Y^{\prime \prime}\left(X^{\prime \prime}+Y^{\prime \prime}\right)+n\left(S^{\prime} X^{\prime \prime} Y^{\prime \prime}\right)^{2}>0$. It follows $k_{x}^{\triangleleft}>k_{x}^{*}$. If we go from the first-best policy to the decentralized policy with the green subsidy, $\theta$ falls by $H+I$ ( since $\mathrm{d} \theta=\theta^{*}-\theta^{\circ}=H+I<0$ ) and $\sigma$ increases by $J$ (since $\left.\mathrm{d} \sigma=\sigma^{*}-\sigma^{o}=J>0\right)$. From (C24) and (C25) follows $k_{x}^{o}<k_{x}^{*}$. The change in $k_{y}$ is

$$
\mathrm{d} k_{y}=\frac{\partial k_{y}}{\partial \theta} \mathrm{d} \theta+\frac{\partial k_{y}}{\partial \sigma} \mathrm{d} \sigma=-\frac{\alpha(n-1)^{2}\left(X^{\prime \prime}+Y^{\prime \prime}-S^{\prime} X^{\prime \prime} Y^{\prime \prime}\right)^{2}}{z_{1} z_{3}} V^{\prime}<0 .
$$

This implies $k_{y}^{o}>k_{y}^{*}$. Overall we obtain $k_{x}^{\Delta}>k_{x}^{*}>k_{x}^{o}$ and $k_{y}^{\Delta}<k_{y}^{*}<k_{y}^{o}$, which is the same result as obtained in Proposition 3 for fixed capital supply. This completes the proof of Proposition 4 in case of endogenous capital supply.

D. Proof of Proposition 5. We again start with the comparative static analysis of the capital market equilibrium, but we will report only those results which are needed for the subsequent analysis. Totally differentiating $X^{\prime}\left(k_{x}\right)=r+\alpha p, Y^{\prime}\left(k_{y}\right)=r-\sigma$, $X^{\prime}\left(\hat{k}_{x}\right)=r, Y^{\prime}\left(\hat{k}_{y}\right)=r, k_{x}+k_{y}+\hat{k}_{x}+\hat{k}_{y}=2 \bar{k}$ and $\alpha k_{x}=q$ yields

$$
\begin{gathered}
\frac{\partial r}{\partial q}=-\frac{Y^{\prime \prime} \hat{X}^{\prime \prime} \hat{Y}^{\prime \prime}}{\alpha\left[\hat{X}^{\prime \prime} \hat{Y}^{\prime \prime}+Y^{\prime \prime}\left(\hat{X}^{\prime \prime}+\hat{Y}^{\prime \prime}\right)\right]}>0, \\
\frac{\partial k_{x}}{\partial q}=\frac{1}{\alpha}>0, \quad \frac{\partial \hat{k}_{x}}{\partial q}=-\frac{Y^{\prime \prime} \hat{Y}^{\prime \prime}}{\alpha\left[\hat{X}^{\prime \prime} \hat{Y}^{\prime \prime}+Y^{\prime \prime}\left(\hat{X}^{\prime \prime}+\hat{Y}^{\prime \prime}\right)\right]}<0, \\
\frac{\partial k_{y}}{\partial q}=-\frac{\hat{X}^{\prime \prime} \hat{Y}^{\prime \prime}}{\alpha\left[\hat{X}^{\prime \prime} \hat{Y}^{\prime \prime}+Y^{\prime \prime}\left(\hat{X}^{\prime \prime}+\hat{Y}^{\prime \prime}\right)\right]}<0,
\end{gathered}
$$


and

$$
\begin{gathered}
\frac{\partial r}{\partial \sigma}=\frac{\hat{X}^{\prime \prime} \hat{Y}^{\prime \prime}}{\hat{X}^{\prime \prime} \hat{Y}^{\prime \prime}+Y^{\prime \prime}\left(\hat{X}^{\prime \prime}+\hat{Y}^{\prime \prime}\right)}>0, \\
\frac{\partial k_{x}}{\partial \sigma}=0, \quad \frac{\partial \hat{k}_{x}}{\partial \sigma}=\frac{\hat{Y}^{\prime \prime}}{\hat{X}^{\prime \prime} \hat{Y}^{\prime \prime}+Y^{\prime \prime}\left(\hat{X}^{\prime \prime}+\hat{Y}^{\prime \prime}\right)}<0, \\
\frac{\partial k_{y}}{\partial \sigma}=-\frac{\hat{X}^{\prime \prime}+\hat{Y}^{\prime \prime}}{\hat{X}^{\prime \prime} \hat{Y}^{\prime \prime}+Y^{\prime \prime}\left(\hat{X}^{\prime \prime}+\hat{Y}^{\prime \prime}\right)}>0 .
\end{gathered}
$$

With $\beta=1$, pollution is given by $e=\alpha\left(k_{x}+\hat{k}_{x}\right)$. Using the comparative static effects derived in (D1)-(D6) yields

$$
\begin{aligned}
& \frac{\partial e}{\partial q}=\frac{\hat{X}^{\prime \prime}\left(Y^{\prime \prime}+\hat{Y}^{\prime \prime}\right)}{\hat{X}^{\prime \prime} \hat{Y}^{\prime \prime}+Y^{\prime \prime}\left(\hat{X}^{\prime \prime}+\hat{Y}^{\prime \prime}\right)}>0, \\
& \frac{\partial e}{\partial \sigma}=\frac{\alpha \hat{Y}^{\prime \prime}}{\hat{X}^{\prime \prime} \hat{Y}^{\prime \prime}+Y^{\prime \prime}\left(\hat{X}^{\prime \prime}+\hat{Y}^{\prime \prime}\right)}<0 .
\end{aligned}
$$

Consumption in the green country is $c=r\left(\bar{k}-k_{x}-k_{y}\right)+X\left(k_{x}\right)+Y\left(k_{y}\right)$. Hence,

$$
\begin{gathered}
\frac{\partial c}{\partial q}=p+\sigma \frac{\hat{X}^{\prime \prime} \hat{Y}^{\prime \prime}}{\alpha\left[\hat{X}^{\prime \prime} \hat{Y}^{\prime \prime}+Y^{\prime \prime}\left(\hat{X}^{\prime \prime}+\hat{Y}^{\prime \prime}\right)\right]}-\frac{\left(\bar{k}-k_{x}-k_{y}\right) Y^{\prime \prime} \hat{X}^{\prime \prime} \hat{Y}^{\prime \prime}}{\alpha\left[\hat{X}^{\prime \prime} \hat{Y}^{\prime \prime}+Y^{\prime \prime}\left(\hat{X}^{\prime \prime}+\hat{Y}^{\prime \prime}\right)\right]}, \\
\frac{\partial c}{\partial \sigma}=\sigma \frac{\hat{X}^{\prime \prime}+\hat{Y}^{\prime \prime}}{\hat{X}^{\prime \prime} \hat{Y}^{\prime \prime}+Y^{\prime \prime}\left(\hat{X}^{\prime \prime}+\hat{Y}^{\prime \prime}\right)}+\frac{\left(\bar{k}-k_{x}-k_{y}\right) \hat{X}^{\prime \prime} \hat{Y}^{\prime \prime}}{\hat{X}^{\prime \prime} \hat{Y}^{\prime \prime}+Y^{\prime \prime}\left(\hat{X}^{\prime \prime}+\hat{Y}^{\prime \prime}\right)},
\end{gathered}
$$

where we used the first-order conditions for profit maximization and the comparative static results derived in (D1)-(D6).

The capital allocation under the different institutional settings is determined by $k_{x}+k_{y}+\hat{k}_{x}+\hat{k}_{y}=2 \bar{k}$ and the conditions (39)-(41) which follow from the first-order conditions of profit maximization. The policy parameters $\theta, \hat{\theta}$ and $\gamma$ take different values, depending on the institutional setting under consideration. The centralized (first-best) policy is exactly the same as in the basic model. Hence, from (25), $\beta=1$ and $n=2$ we obtain (42). In the decentralized economy, the green country maximizes the welfare function $U(c, e)$. In the case without the green subsidy, we set $\partial u / \partial q=0$ and use $\sigma \equiv 0,(\mathrm{D} 7)$ and (D9) in order to obtain

$$
p^{\triangle}=-\frac{\hat{X}^{\prime \prime}\left(Y^{\prime \prime}+\hat{Y}^{\prime \prime}\right)}{\hat{X}^{\prime \prime} \hat{Y}^{\prime \prime}+Y^{\prime \prime}\left(\hat{X}^{\prime \prime}+\hat{Y}^{\prime \prime}\right)} \frac{U_{e}}{U_{c}}+\frac{\left(\bar{k}-k_{x}^{\triangle}-k_{y}^{\triangleleft}\right) Y^{\prime \prime} \hat{X}^{\prime \prime} \hat{Y}^{\prime \prime}}{\alpha\left[\hat{X}^{\prime \prime} \hat{Y}^{\prime \prime}+Y^{\prime \prime}\left(\hat{X}^{\prime \prime}+\hat{Y}^{\prime \prime}\right)\right]} .
$$

Note that $\bar{k}-k_{x}^{\Delta}-k_{y}^{\Delta}>0$ according to $X^{\prime}\left(\hat{k}_{x}\right)=X^{\prime}\left(k_{x}\right)-\alpha p^{\Delta}<X^{\prime}\left(k_{x}\right), Y^{\prime}\left(\hat{k}_{y}\right)=$ $Y^{\prime}\left(k_{y}\right)$ and $k_{x}+k_{y}+\hat{k}_{x}+\hat{k}_{y}=2 \bar{k}$. Hence, the green country exports capital and the 
last term in (D11) represents the terms of trade effect mentioned in the interpretation of Proposition 5. Setting $\theta=\alpha p^{\triangle}$ and $\hat{\theta}=\gamma=0$ proves (43).

If the green subsidy is available, we can use the same procedure as in the basic model in order to show that the green country chooses $\sigma^{*}>0$. From the first-order conditions $\partial u / \partial q=0$ and $\partial u / \partial \sigma=0$ and the comparative static results in (D7)-(D10) we obtain after some tedious computations

$$
\begin{aligned}
p^{*} & =-\frac{\hat{X}^{\prime \prime}}{\hat{X}^{\prime \prime}+\hat{Y}^{\prime \prime}} \frac{U_{e}}{U_{c}}+\frac{\left(\bar{k}-k_{x}^{*}-k_{y}^{*}\right) \hat{X}^{\prime \prime} \hat{Y}^{\prime \prime}}{\alpha\left(\hat{X}^{\prime \prime}+\hat{Y}^{\prime \prime}\right)}, \\
\sigma^{*} & =-\alpha \frac{\hat{Y}^{\prime \prime}}{\hat{X}^{\prime \prime}+\hat{Y}^{\prime \prime}} \frac{U_{e}}{U_{c}}-\frac{\left(\bar{k}-k_{x}^{*}-k_{y}^{*}\right) \hat{X}^{\prime \prime} \hat{Y}^{\prime \prime}}{\alpha\left(\hat{X}^{\prime \prime}+\hat{Y}^{\prime \prime}\right)} .
\end{aligned}
$$

The last term in (D13) represents the terms of trade effect of the green subsidy mentioned in the main text. Combining (D12) and (D13) yields $\alpha p^{*}+\sigma^{*}=-\alpha U_{e} / U_{c}$. Setting $\theta=\alpha p^{*}+\sigma^{*}, \hat{\theta}=0$ and $\gamma=-\sigma^{*}$ proves (44).

As stated in the text, for general production and utility functions the comparison of the capital allocations is untractable. However, for the special case of $X\left(k_{x}\right)=$ $a_{x} k_{x}-b_{x} k_{x}^{2} / 2, Y\left(k_{y}\right)=a_{y} k_{y}-b_{y} k_{y}^{2} / 2$ and $U(c, e)=c-f e$ with $a_{x}, a_{y}, b_{x}, b_{y}, f>0$, we obtain from (39)-(44) the first-best capital allocation

$$
k_{x}^{o}=\hat{k}_{x}^{o}=\frac{a_{x}-a_{y}+b_{y} \bar{k}-2 \alpha f}{b_{x}+b_{y}}, \quad k_{y}=\hat{k}_{y}=\frac{a_{y}-a_{x}+b_{x} \bar{k}+2 \alpha f}{b_{x}+b_{y}},
$$

the decentralized capital allocation without the green subsidy

$$
\begin{gathered}
k_{x}^{\Delta}=\frac{\left(a_{x}-a_{y}+b_{y} \bar{k}\right)\left(4 b_{x}+3 b_{y}\right)-2\left(2 b_{x}+b_{y}\right) f \alpha}{\left(b_{x}+b_{y}\right)\left(4 b_{x}+3 b_{y}\right)}, \\
\hat{k}_{x}^{\Delta}=\frac{\left(a_{x}-a_{y}+b_{y} \bar{k}\right)\left(4 b_{x}+3 b_{y}\right)+2 b_{y} f \alpha}{\left(b_{x}+b_{y}\right)\left(4 b_{x}+3 b_{y}\right)}, \\
k_{y}^{\Delta}=\hat{k}_{y}^{\Delta}=\frac{\left(a_{y}-a_{x}+b_{x} \bar{k}\right)\left(4 b_{x}+3 b_{y}\right)+2 b_{x} f \alpha}{\left(b_{x}+b_{y}\right)\left(4 b_{x}+3 b_{y}\right)},
\end{gathered}
$$

and the decentralized capital allocation with the green subsidy

$$
\begin{array}{ll}
k_{x}^{*}=\frac{a_{x}-a_{y}+b_{y} \bar{k}-f \alpha}{b_{x}+b_{y}}, & \hat{k}_{x}^{*}=\frac{a_{x}-a_{y}+b_{y} \bar{k}}{b_{x}+b_{y}}, \\
k_{y}^{*}=\frac{a_{y}-a_{x}+b_{x} \bar{k}+f \alpha}{b_{x}+b_{y}}, & \hat{k}_{y}^{*}=\frac{a_{y}-a_{x}+b_{x} \bar{k}}{b_{x}+b_{y}} .
\end{array}
$$

By comparing these capital allocations it is straightforward to show that $k_{x}^{\Delta}>k_{x}^{*}>k_{x}^{o}$, $k_{y}^{\Delta}<k_{y}^{*}<k_{y}^{o}, \hat{k}_{x}^{\Delta}>\hat{k}_{x}^{*}>\hat{k}_{x}^{o}$ and $\hat{k}_{y}^{*}<\hat{k}_{y}^{\Delta}<\hat{k}_{y}^{o}$ which proves Proposition 5 . 


\section{CESifo Working Paper Series}

for full list see www.cesifo-group.org/wp

(address: Poschingerstr. 5, 81679 Munich, Germany, office@cesifo.de)

3120 Laszlo Goerke and Markus Pannenberg, 'Take it or Go to Court' - The Impact of Sec. 1a of the German Protection against Dismissal Act on Severance Payments -, July 2010

3121 Robert S. Chirinko and Daniel J. Wilson, Can Lower Tax Rates be Bought? Business Rent-Seeking and Tax Competition among U.S. States, July 2010

3122 Douglas Gollin and Christian Zimmermann, Global Climate Change and the Resurgence of Tropical Disease: An Economic Approach, July 2010

3123 Francesco Daveri and Maria Laura Parisi, Experience, Innovation and Productivity Empirical Evidence from Italy's Slowdown, July 2010

3124 Carlo V. Fiorio and Massimo Florio, A Fair Price for Energy? Ownership versus Market Opening in the EU15, July 2010

3125 Frederick van der Ploeg, Natural Resources: Curse or Blessing?, July 2010

3126 Kaisa Kotakorpi and Panu Poutvaara, Pay for Politicians and Candidate Selection: An Empirical Analysis, July 2010

3127 Jun-ichi Itaya, Makoto Okamura and Chikara Yamaguchi, Partial Tax Coordination in a Repeated Game Setting, July 2010

3128 Volker Meier and Helmut Rainer, On the Optimality of Joint Taxation for NonCooperative Couples, July 2010

3129 Ryan Oprea, Keith Henwood and Daniel Friedman, Separating the Hawks from the Doves: Evidence from Continuous Time Laboratory Games, July 2010

3130 Mari Rege and Ingeborg F. Solli, The Impact of Paternity Leave on Long-term Father Involvement, July 2010

3131 Olaf Posch, Risk Premia in General Equilibrium, July 2010

3132 John Komlos and Marek Brabec, The Trend of BMI Values by Centiles of US Adults, Birth Cohorts 1882-1986, July 2010

3133 Emin Karagözoğlu and Arno Riedl, Information, Uncertainty, and Subjective Entitlements in Bargaining, July 2010

3134 John Boyd, Gianni De Nicolò and Elena Loukoianova, Banking Crises and Crisis Dating: Theory and Evidence, July 2010

3135 Michael R. Baye, Dan Kovenock and Casper G. de Vries, The Herodotus Paradox, July 2010 
3136 Martin Kolmar and Hendrik Rommeswinkel, Group Contests with Complementarities in Efforts, July 2010

3137 Carolina Manzano and Xavier Vives, Public and Private Learning from Prices, Strategic Substitutability and Complementarity, and Equilibrium Multiplicity, July 2010

3138 Axel Löffler, Gunther Schnabl and Franziska Schobert, Inflation Targeting by Debtor Central Banks in Emerging Market Economies, July 2010

$3139 \mathrm{Yu}-\mathrm{Fu}$ Chen and Michael Funke, Global Warming and Extreme Events: Rethinking the Timing and Intensity of Environmental Policy, July 2010

3140 Lawrence M. Kahn, Labor Market Policy: A Comparative View on the Costs and Benefits of Labor Market Flexibility, July 2010

3141 Ben J. Heijdra, Jochen O. Mierau and Laurie S.M. Reijnders, The Tragedy of Annuitization, July 2010

3142 Erkki Koskela, Outsourcing Cost and Tax Progression under Nash Wage Bargaining with Flexible Outsourcing, July 2010

3143 Daniel Osberghaus and Christiane Reif, Total Costs and Budgetary Effects of Adaptation to Climate Change: An Assessment for the European Union, August 2010

3144 Philip E. Graves, Benefit-Cost Analysis of Environmental Projects: A Plethora of Systematic Biases, August 2010

3145 Sabrina Di Addario and Daniela Vuri, Entrepreneurship and Market Size. The Case of Young College Graduates in Italy, August 2010

3146 Shoshana Amyra Grossbard and Alfredo Marvăo Pereira, Will Women Save more than Men? A Theoretical Model of Savings and Marriage, August 2010

3147 Jarko Fidrmuc, Time-Varying Exchange Rate Basket in China from 2005 to 2009, August 2010

3148 Ilja Neustadt and Peter Zweifel, Is the Welfare State Sustainable? Experimental Evidence on Citizens' Preferences for Redistribution, August 2010

3149 Marcus Dittrich and Andreas Knabe, Wage and Employment Effects of Non-Binding Minimum Wages, August 2010

3150 Shutao Cao, Enchuan Shao and Pedro Silos, Fixed-Term and Permanent Employment Contracts: Theory and Evidence, August 2010

3151 Ludger Woessmann, Cross-Country Evidence on Teacher Performance Pay, August 2010

3152 Lorenzo C. G. Pozzi, Casper G. de Vries and Jorn Zenhorst, World Equity Premium Based Risk Aversion Estimates, August 2010 
3153 Volker Grossmann, Thomas M. Steger and Timo Trimborn, Dynamically Optimal R\&D Subsidization, August 2010

3154 Alexander Haupt, Tim Krieger and Thomas Lange, A Note on Brain Gain and Brain Drain: Permanent Migration and Education Policy, August 2010

3155 António Afonso and Christophe Rault, Long-run Determinants of Sovereign Yields, August 2010

3156 Franziska Tausch, Jan Potters and Arno Riedl, Preferences for Redistribution and Pensions. What can we Learn from Experiments?, August 2010

3157 Martin Kolmar and Andreas Wagener, Inefficient Group Organization as Optimal Adaption to Dominant Environments, August 2010

3158 Kai Carstensen, Klaus Wohlrabe and Christina Ziegler, Predictive Ability of Business Cycle Indicators under Test: A Case Study for the Euro Area Industrial Production, August 2010

3159 Horst Rottmann and Timo Wollmershäuser, A Micro Data Approach to the Identification of Credit Crunches, August 2010

3160 Philip E. Graves, Appropriate Fiscal Policy over the Business Cycle: Proper Stimulus Policies Can Work, August 2010

3161 Michael Binder and Marcel Bluhm, On the Conditional Effects of IMF Program Participation on Output Growth, August 2010

3162 Michael Binder, Qianying Chen, and Xuan Zhang, On the Effects of Monetary Policy Shocks on Exchange Rates, August 2010

3163 Felix J. Bierbrauer, On the Optimality of Optimal Income Taxation, August 2010

3164 Nikolaus Wolf, Europe's Great Depression - Coordination Failure after the First World War, September 2010

3165 Dan Kovenock and Brian Roberson, Conflicts with Multiple Battlefields, September 2010

3166 Jean-Pierre Ponssard and Catherine Thomas, Capacity Investment under Demand Uncertainty. An Empirical Study of the US Cement Industry, 1994-2006, September 2010

3167 Jørgen Juel Andersen, Jon H. Fiva and Gisle James Natvik, Voting when the Stakes are High, September 2010

3168 Michael Hoel, Is there a Green Paradox?, September 2010

3169 Scott Alan Carson, Nineteenth Century US African-American and White Female Statures: Insight from US Prison Records, September 2010 
3170 Gil S. Epstein, Yosef Mealem and Shmuel Nitzan, Political Culture and Discrimination in Contests, September 2010

3171 Sara Fisher Ellison, Jeffrey Greenbaum and Wallace P. Mullin, Diversity, Social Goods Provision, and Performance in the Firm, September 2010

3172 Silvia Dominguez-Martinez, Randolph Sloof and Ferdinand von Siemens, Monitoring your Friends, not your Foes: Strategic Ignorance and the Delegation of Real Authority, September 2010

3173 Marcus Dittrich and Beate Schirwitz, Union Membership and Employment Dynamics: A Note, September 2010

3174 Francesco Daveri, Paolo Manasse and Danila Serra, The Twin Effects of Globalization - Evidence from a Sample of Indian Manufacturing Firms, September 2010

3175 Florian Blöchl, Fabian J. Theis, Fernando Vega-Redondo and Eric O’N. Fisher, Which Sectors of a Modern Economy are most Central?, September 2010

3176 Dag Morten Dalen, Marilena Locatelli and Steinar Strøm, Longitudinal Analysis of Generic Substitution, September 2010

3177 Armin Falk, Stephan Meier and Christian Zehnder, Did we Overestimate the Role of Social Preferences? The Case of Self-Selected Student Samples, September 2010

3178 Christian Fahrholz and Cezary Wójcik, The Bail-Out! Positive Political Economics of Greek-type Crises in the EMU, September 2010

3179 Klaus Abberger and Wolfgang Nierhaus, The Ifo Business Cycle Clock: Circular Correlation with the Real GDP, September 2010

3180 Walter Krämer and Gerhard Arminger, "True Believers" or Numerical Terrorism at the Nuclear Power Plant, September 2010

3181 Bernard M.S. Van Praag, Dmitri Romanov and Ada Ferrer-i-Carbonell, Happiness and Financial Satisfaction in Israel. Effects of Religiosity, Ethnicity, and War, September 2010

3182 Dimitrios Koumparoulis and Paul De Grauwe, Public Capital, Employment and Productivity: An Empirical Investigation for Greece, September 2010

3183 John Whalley and Tanmaya Shekhar, The Rapidly Deepening India-China Economic Relationship, September 2010

3184 Andreas Schäfer and Thomas Steger, History, Expectations, and Public Policy: Economic Development in Eastern Germany, September 2010

3185 Thomas Eichner and Marco Runkel, Subsidizing Renewable Energy under Capital Mobility, September 2010 